\title{
Review \\ Black Phosphorus as Multifaceted Advanced Material Nanoplatforms for Potential Biomedical Applications
}

\author{
Abhijeet Pandey ${ }^{1}$, Ajinkya N. Nikam ${ }^{1} \oplus$, Gasper Fernandes ${ }^{1}$, Sanjay Kulkarni ${ }^{1}$, Bharath Singh Padya ${ }^{1}$, \\ Ruth Prass1 ${ }^{2}{ }^{\circ}$, Subham Das ${ }^{3}$, Alex Joseph ${ }^{3}$, Prashant K. Deshmukh ${ }^{4}$, Pravin O. Patil ${ }^{5}$ and Srinivas Mutalik ${ }^{1, *}$ \\ 1 Department of Pharmaceutics, Manipal College of Pharmaceutical Sciences, Manipal Academy of Higher \\ Education, Manipal 576104, Karnataka, India; abhijeet.pandey@manipal.edu (A.P.); \\ ajinkya.nikam7@gmail.com (A.N.N.); fernandesgasper16@gmail.com (G.F.); sanjay987k@gmail.com (S.K.); \\ bharathsatavahana@gmail.com (B.S.P.) \\ 2 Gottfried Schatz Research Centre for Cell Signalling, Metabolism and Aging, Medical University of Graz, \\ 8036 Graz, Austria; ruth.prassl@medunigraz.at \\ 3 Department of Pharmaceutical Chemistry, Manipal College of Pharmaceutical Sciences, \\ Manipal Academy of Higher Education, Manipal 576104, Karnataka, India; \\ subhamdas4646@gmail.com (S.D.); alex.joseph@manipal.edu (A.J.) \\ 4 Department of Pharmaceutics, Dr. Rajendra Gode College of Pharmacy, Buldhana 443101, Maharashtra, India; \\ pkdesh@gmail.com \\ 5 Department of Pharmaceutical Chemistry, H R Patel Institute of Pharmaceutical Education and Research, \\ Karwand Naka, Shirpur, Dist Dhule 425405, Maharashtra, India; rxpatilpravin@yahoo.co.in \\ * Correspondence: ss.mutalik@manipal.edu
}

Citation: Pandey, A.; Nikam, A.N.; Fernandes, G.; Kulkarni, S.; Padya, B.S.; Prassl, R.; Das, S.; Joseph, A.; Deshmukh, P.K.; Patil, P.O.; Mutalik, S. Black Phosphorus as Multifaceted Advanced Material Nanoplatforms for Potential Biomedical Applications Nanomaterials 2021, 11, 13. https:// dx.doi.org/10.3390/nano11010013

Received: 6 November 2020 Accepted: 19 December 2020 Published: 23 December 2020

Publisher's Note: MDPI stays neutral with regard to jurisdictional claims in published maps and institutional affiliations.

Copyright: () 2020 by the authors. Licensee MDPI, Basel, Switzerland. This article is an open access article distributed under the terms and conditions of the Creative Commons Attribution (CC BY) license (https: / / creativecommons.org/ licenses/by/4.0/).

\begin{abstract}
Black phosphorus is one of the emerging members of two-dimensional (2D) materials which has recently entered the biomedical field. Its anisotropic properties and infrared bandgap have enabled researchers to discover its applicability in several fields including optoelectronics, 3D printing, bioimaging, and others. Characterization techniques such as Raman spectroscopy have revealed the structural information of Black phosphorus (BP) along with its fundamental properties, such as the behavior of its photons and electrons. The present review provides an overview of synthetic approaches and properties of BP, in addition to a detailed discussion about various types of surface modifications available for overcoming the stability-related drawbacks and for imparting targeting ability to synthesized nanoplatforms. The review further gives an overview of multiple characterization techniques such as spectroscopic, thermal, optical, and electron microscopic techniques for providing an insight into its fundamental properties. These characterization techniques are not only important for the analysis of the synthesized BP but also play a vital role in assessing the doping as well as the structural integrity of BP-based nanocomposites. The potential role of BP and BP-based nanocomposites for biomedical applications specifically, in the fields of drug delivery, $3 \mathrm{D}$ printing, and wound dressing, have been discussed in detail to provide an insight into the multifunctional role of BP-based nanoplatforms for the management of various diseases, including cancer therapy. The review further sheds light on the role of BP-based 2D platforms such as BP nanosheets along with BP-based OD platforms-i.e., BP quantum dots in the field of therapy and bioimaging of cancer using techniques such as photoacoustic imaging and fluorescence imaging. Although the review inculcates the multimodal therapeutic as well as imaging role of $\mathrm{BP}$, there is still research going on in this field which will help in the development of BP-based theranostic platforms not only for cancer therapy, but various other diseases.
\end{abstract}

Keywords: bioimaging; wound healing; 3D printing; surface modification; characterization

\section{Introduction}

The discovery of Black Phosphorus (BP) dates back to a hundred years ago. It all began with Bridgman [1], who brought about the conversion of white phosphorus to black phosphorus under a high temperature and pressure. Later, Hultgren et al. [2] demonstrated 
the orthorhombic structure of BP using X-ray diffraction and also found that BP was a thermodynamically stable allotrope of phosphorus. BP has a lot in common with graphite, including its structural, physical, and electronic properties. As graphene has a wide spread application in the biomedical field [3], similarly, BP is also being explored for its utility in biomedicine. For instance, few-layer BP (FLBP), due to its structure, photonic properties, biodegradability, and low toxicity, has been exploited for drug delivery, bioimaging, phototherapy, and combination therapeutic strategies [4]. The phosphorus atoms in BP are arranged in the form of puckered honeycomb layers connected via weak interlayer van der Waals forces and strong intralayer bonding between $P$ atoms [5]. Its unique properties, such as tunable band gap, high carrier mobility, and anisotropic properties, has enabled its application in various physical and chemical fields [6].

The interaction between biological systems and BP has been explained to a certain level, which details basic information for modifying the physicochemical properties of black phosphorous to enhance the efficacy in therapeutic applications and reduce the unforeseen side effects. Research conducted by Chen and team [7] emphasized that by crossing the blood brain barrier (BBB) and acting as a neuroprotective agent in various diseases such as Parkinson's and Alzheimer's disease, BP nanocomposites can absorb excess transition metals, such as copper, by specifically protecting the neuronal cells from neurotoxicity induced by copper. Although there are many papers describing synthesis approaches and their biomedical applications for cancer, very few papers have focused on their application in different diseases. In this review, we describe the synthesis methods of BP and provide a detailed description of different surface modification strategies using peptides, drugs, polymers, aptamers, and lipids. We have also discussed several characterization techniques such as spectroscopic, thermal, optical, and electron microscopic techniques. A comprehensive section is dedicated to the biomedical applications of BP in drug delivery for different diseases such as bone therapy, wound healing, cancer therapy, and neurodegenerative diseases. The application of $\mathrm{BP}$ in $3 \mathrm{D}$ printing and bioimaging is also discussed.

\section{Synthesis}

Bulk BP is extremely stable, especially in comparison to other allotropes, due to its robust hydrophilic property, oxidation state, and its low-dimensional form-i.e., few-layer or monolayer BP is very unstable. Furthermore, heating can endorse degradation of BP [8]. In 1981, by using white phosphorus (WP) and liquid bismuth at a temperature of $300{ }^{\circ} \mathrm{C}$ below 0.5 MPa, Maruyama et al. discovered the process to synthesize BP under considerably moderate pressure [9]. Unlike the methods of synthesis using WP as described above, researchers eventually started selecting red phosphorus (RP) as a raw material for producing BP to avoid the toxicity of WP [10]. Lange et al. found, in 2007, that BP can be produced from RP by adding gold, nickel, and nickel (IV) iodide in smaller amounts at $600{ }^{\circ} \mathrm{C}$ under low-pressure state [11]. Later, in the year 2014, Kopf et al. suggested that BP can be produced with RP, tin and tin (IV) iodide additives utilizing a short-way transport reaction [12]. The $\mathrm{Sn}-\mathrm{SnI}_{4}$, an $\mathrm{RP}$ mixture-was placed in the furnace at $650{ }^{\circ} \mathrm{C}$. For the synthesis of $\mathrm{BP}$, the mixture was cooled down to the $550{ }^{\circ} \mathrm{C}$ within $7.5 \mathrm{~h}$. They succeeded


previous approach by Lange et al. [11].

Very recently, the fabrication of BP nanomaterials has gained a broader perspective and was divided into two general strategies-namely, the bottom-up method and the top-down method. The bottom-up approach involves direct chemical synthesis of nanomaterials using a particular precursor (red phosphorus [13]), whereas the top-down approach focuses on exfoliation of the bulk material using driving force to break it down to nanometric size by means of chemical and mechanical exfoliation (Figure 1). A well elaborated review on the synthesis of BP has been reported by Boddula et al. [14]. Hence, in the following section we have summarized the importance of different synthetic schemes, addressing drawbacks and describing the most feasible synthesis for the scale up of BP nanomaterials. In a 
mechanical exfoliation approach, an adhesive tape is used and monolayer BP is peeled off from bulk BP. The most commonly used methods for the preparation of BP nanomaterials along with their mechanisms, advantages, and disadvantages are described in Table 1.

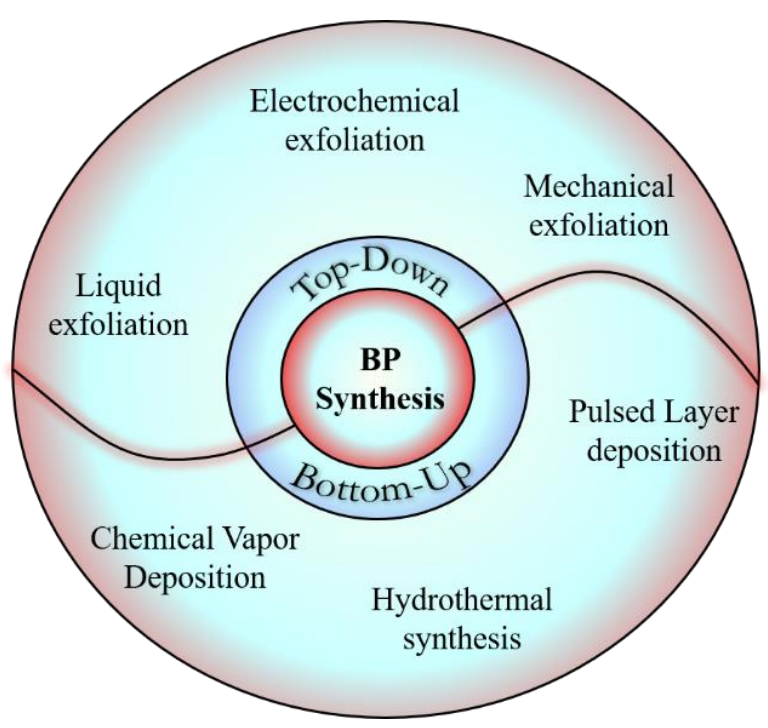

Figure 1. Schematic representation of various synthesis strategies for fabricating two-dimensional (2D) materials.

The monolayers of BP synthesized from the methods such as chemical vapor deposition and mechanical exfoliation are usually situated at the edge of thick sheets and are too small to process and characterize. Along with this, the inherent problems related to phosphorous, such as weaker P-P bonds, leading to its oxidation and others, pose a challenge in developing a suitable method which is practically applicable and can be scaled up for commercial synthesis. In this context, the liquid exfoliation method serves this purpose and is widely used for the synthesis of BP and related 2D nanomaterials [15,16]. This method yields nanosheets in the form of liquid-suspension that can be further processed into nanocomposites, films, and other structures. It has been extensively used and proved to be successful in exfoliating a large variety of layered crystals such as metal oxides, graphite, and chalcogenides [16]. Liquid-phase exfoliation is the simplest method that includes sonication of layered crystals to give nanosheets using stabilizing liquids such as solvents [17]/polymer solutions [18]/aqueous surfactants [19]. The repulsive forces between adjacent polymer/surfactant-coated nanosheets provide stabilization to the nanosheets. When solvents are used for stabilization, it is presumed that solvents with either appropriate solubilities or surface energy parameters bind to nanosheets with internanosheet binding strength through van der Waals interactions [20]. This lowers the net cost of energy utilized in exfoliation. These principles of exfoliation are not specific to 2D materials and can be applied to a broad spectrum of layered compounds. In fact, this method has already been utilized for a variety of transition-metal dichalcogendes (TMDs), graphene, and molybdenum disulfide $\left(\mathrm{MoS}_{2}\right)[17,21]$ due to a plethora of advantages such as quick and easier synthesis, being sturdy to environmental conditions, and flexibility in terms of scaling up. Several studies have already reported the biomedical applications of BP nanomaterials, such as bioimaging and phototherapy, synthesized by this method [22]. Thus, liquid exfoliation can be a potential route of synthesis for the fabrication of BP and related 2D nanomaterials at a commercial scale for biomedical applications. 
Table 1. Most commonly used methods for the synthesis of black phosphorous (BP) nanomaterials along with their mechanisms, advantages, and disadvantages.

\begin{tabular}{|c|c|c|c|c|c|}
\hline Method & Mechanism & $\begin{array}{l}\text { Application } \\
\text { Materials }\end{array}$ & Advantages & Disadvantages & Reference \\
\hline $\begin{array}{l}\text { Liquid } \\
\text { exfoliation }\end{array}$ & $\begin{array}{c}\text { Cleavage of } \\
\text { multilayered crystals } \\
\text { dispersed in a solvent in } \\
\text { the presence of } \\
\text { ultrasonic energy } \\
\text { Exfoliation of lavers }\end{array}$ & $\begin{array}{l}\text { Transistors, optical } \\
\text { devices, super } \\
\text { capacitors, sensors, } \\
\text { photocatalysts, } \\
\text { bioimaging etc. }\end{array}$ & $\begin{array}{l}\text { Quick, easier, and } \\
\text { sturdy to } \\
\text { environmental } \\
\text { conditions and } \\
\text { flexible to scale up. }\end{array}$ & $\begin{array}{l}\text { Difficult to control } \\
\text { the thickness of the } \\
\text { layered crystals }\end{array}$ & [22] \\
\hline $\begin{array}{c}\text { Electrochemical } \\
\text { Method }\end{array}$ & $\begin{array}{l}\text { Exfoliation of layers } \\
\text { occur by applying } \\
\text { voltage between anode } \\
\text { and cathode that are } \\
\text { usually dipped in an } \\
\text { acidic solution }\end{array}$ & $\begin{array}{l}\text { Most commonly } \\
\text { used for synthesis of } \\
\text { graphene from } \\
\text { graphite }\end{array}$ & $\begin{array}{l}\text { Various metal 2D } \\
\text { nanosheets can be } \\
\text { prepared. }\end{array}$ & $\begin{array}{l}\text { Harmful and toxic } \\
\text { chemicals are used }\end{array}$ & [23] \\
\hline $\begin{array}{l}\text { Mechanical } \\
\text { Exfoliation } \\
\text { Method }\end{array}$ & $\begin{array}{l}\text { A scotch tape process } \\
\text { that repeatedly peels off } \\
\text { various layers from } \\
\text { multilayer } \\
\text { crystals/sheets }\end{array}$ & $\begin{array}{l}\text { Imaging, photonic } \\
\text { devices, coating, } \\
\text { electronic devices, } \\
\text { advanced } \\
\text { composites, energy } \\
\text { storage, metrology, } \\
\text { paint, sensors }\end{array}$ & $\begin{array}{l}\text { No chemical is } \\
\text { required and } \\
\text { eco-friendly }\end{array}$ & $\begin{array}{l}\text { Time consuming, no } \\
\text { uniform thickness of } \\
\text { the product, low } \\
\text { yield, and is not } \\
\text { scalable }\end{array}$ & [24] \\
\hline $\begin{array}{c}\text { Plasma Etching } \\
\text { Method }\end{array}$ & $\begin{array}{l}\text { An oxidation process } \\
\text { where monolayer is } \\
\text { placed on a silica } \\
\text { substrate which is } \\
\text { exposed to oxygen } \\
\text { plasma, due to which } \\
\text { the surface layer gets } \\
\text { oxidized }\end{array}$ & $\begin{array}{l}\text { Optoelectronics and } \\
\text { nanoelectronics }\end{array}$ & $\begin{array}{l}\text { Water soluble, Most } \\
\text { commonly used in } \\
\text { multiple layered } \\
\text { hexagonal carbides } \\
\text { and nitrides (MAX) } \\
\text { materials }\end{array}$ & $\begin{array}{l}\text { Toxic chemicals such } \\
\text { as hydrofluoric acid } \\
\text { is used; time } \\
\text { consuming }\end{array}$ & [25] \\
\hline $\begin{array}{l}\text { Chemical Vapour } \\
\text { deposition (CVD) } \\
\text { Method }\end{array}$ & $\begin{array}{l}\text { A coating process where } \\
\text { the precursors, gas, or } \\
\text { vapor, can react or } \\
\text { decompose on the } \\
\text { preselected substrate at } \\
\text { high temperature and } \\
\text { vacuum in a chamber }\end{array}$ & $\begin{array}{l}\text { For synthesis of } 2 \mathrm{D} \\
\text { nanomaterials and } \\
\text { thin films on solid } \\
\text { substrates }\end{array}$ & $\begin{array}{l}\text { High-quality } \\
\text { product, large } \\
\text { surface area }\end{array}$ & $\begin{array}{c}\text { Sensitive and } \\
\text { expensive method } \\
\text { that involves toxic } \\
\text { gases }\end{array}$ & [26] \\
\hline
\end{tabular}

\section{Optical and Electronic Properties}

Because of its crystalline lattice, the anisotropic characteristics of BP are significantly greater than most other 2D materials. Previous reports mainly focused on BP optical anisotropy in the Near infrared region (NIR) [27] until BP anisotropy was identified in the visible region [28]. A group of scientists [29] outlined a sophisticated experimental investigation on the optical anisotropy of BP by integrating existing spectral techniques and a specialized imaging technique. This exemplary tailoring could help both to determine the crystallographic alignment and characterize the surface of BP crystals. It demonstrates optical anisotropy by absorbing polarized light in the direction of the armchair, while transmitting polarized light in a zigzag path [30]. It is also observed that the optical properties are strain-dependent (amount of deformation) [31], and the optical bandgap can be tuned from one atomic layer 0.38 to $2.07 \mathrm{eV}$ by the biaxial strain. Strain engineering can, therefore, regulate BP's optical response. Furthermore, the number of stacked layers not only affects the ability of electrons to interact, but also controls the excitonic effects and optical spectra of BP. Phosphorene is used in optical linear polarizers [32] because of its ability to absorb IR and visible light and also has showed layer-dependent photoluminescence, wherein the luminescence intensity in bilayer BP was reported to be much higher than the intensity in five-layer BP [33]. 
Monolayer BP, on the other hand, displays excellent carrier mobility (up to $1000 \mathrm{~cm}^{2} / \mathrm{Vs}$ ) due to its elevated sensitivity to electrical disturbance, which is superior to metal transition dichalcogenides and has a direct bandgap that can be tuned with the strain applied. This makes it possible to accurately detect incompatible and dissociated gaseous molecules, especially of toxic gases. Because of this property, BP can also be used in immunosensors in addition to gas sensors for antigen-antibody interaction detection [13]. It has already been observed that the value of BP's bandgap increases with the reduction in the number of layers. The direct-indirect-direct transformation in the bandgap of 2D phosphorene is generated by the addition of axial pressure. For the transformation to take place in the zigzag direction, only $2 \%$ compression is required [34]. BP may also undergo semiconductor to metal transition after mild deformation [35]. In a theoretical study, it was proposed that the removal of a few atoms from the BP monolayer would result in the creation of a honeycomb-like structure consisting of two sublattices arranged in a zigzag way [36]. Such an arrangement is known as blue phosphorene which can act as an indirect semiconductor with a bandgap of $\sim 2 \mathrm{eV}$. This tuning of the bandgap in BP allows it to have many electrical properties. Various other phosphorous polymorphs, such as $\delta$ phosphorous [37], g phosphorous [38], and $\beta$ phosphorous [39], were also expected to have stabilities similar to that of $\mathrm{BP}$, based on average ab initio density calculations. The incorporation of these distinct phosphorene polymorphs into a monolayer heterostructure forms the foundation for enabling dual (metallic and semiconducting) conduction in a single layer of material [40]. Therefore, phosphorene and few-layer BP could be great candidates for optoelectronic applications through atomic-level engineering [41].

\section{Surface Modification of Black Phosphorus}

As an evolving component of two-dimensional (2D) nanoparticles, BP-based nanoparticles exhibit great physicochemical characteristics and have great potential for use in modern nanomaterials. Even then, owing to their degradability and in vivo interactions with biomolecules such as plasma proteins, bare BP-based nanoparticles probably reduce their biomedical operations, majorly limiting their potential application in the biomedical arena. Surface engineering offers key techniques for the development of biomaterials of the next generation since the interactions among man-made substances and the biological environment occurs at the surface. A number of surface modifications have been established for BP-based nanoparticles using peptides, drugs, polymers, lipids, aptamers, and antibodies to overcome these drawbacks and obtain stable and effective clinical outcomes, thereby highlighting the advancement of multifunctional BP-based nanoparticles in the biomedical field for more functional use. The section below highlights the current progress in the surface modification of BP-based nanoparticles and Table 2 summarizes the various surface-modified BP nanomaterials and their advantages.

Table 2. Surface modification of BP and its advantages.

\begin{tabular}{|c|c|c|c|}
\hline Functionalized Material & Modification Using & Advantages & Reference \\
\hline BP@FKK Complex & $\begin{array}{l}\text { Tripeptide Fmoc-Lys-Lys-Phe } \\
\text { (Fmoc-KKF) }\end{array}$ & $\begin{array}{l}\text { improved stability; improved cellular } \\
\text { uptake; favorable cell compatibility. }\end{array}$ & [42] \\
\hline $\begin{array}{l}\text { DFBP nanosheets } \\
\text { (MTP-BP-al-PEG) }\end{array}$ & $\begin{array}{l}\text { Mitochondrial Targeting Peptide (MTP) } \\
\text { and acid-labile polymer shell }\end{array}$ & $\begin{array}{l}\text { improved stability; ability to accumulate } \\
\text { in tumor tissue; target mitochondria. } \\
\text { preserves surface morphology; }\end{array}$ & [43] \\
\hline Pt@BP & Cisplatin & $\begin{array}{l}\text { significant cellular uptake rate; improved } \\
\text { cisplatin-resistant cancer cell lines (A2780 } \\
\text { and HepG2) drug response. }\end{array}$ & {$[44]$} \\
\hline PEG-modified BPQDs & PEG & $\begin{array}{l}\text { Increased stability in the physiological } \\
\text { medium; no observable toxicity. }\end{array}$ & {$[45]$} \\
\hline FA-PEG@BPQD@DOX & PEG-NH2-FA & $\begin{array}{l}\text { Better PTT effect; precise targeting } \\
\text { capability for tumor ablation. }\end{array}$ & {$[46]$} \\
\hline
\end{tabular}


Table 2. Cont

\begin{tabular}{|c|c|c|c|}
\hline Functionalized Material & Modification Using & Advantages & Reference \\
\hline BP@PDA-PEG-FA & HS-PEG-FA; Polydopamine & $\begin{array}{c}\text { Synergistic therapy combining } \\
\text { chemotherapy with photothermal } \\
\text { therapy; enhanced stability; targeting } \\
\text { ability for cancer cells. }\end{array}$ & [47] \\
\hline PLL-BP-Apt & anti-Mb DNA aptamer & $\begin{array}{l}\text { Electrochemical-based sensing for the } \\
\text { qualitative and quantitative recognition } \\
\text { of the cardiac disease biomarker, } \mathrm{Mb} \text {; } \\
\text { high sensitivity and specificity for } \mathrm{Mb} \text {; } \\
\text { potential in POC diagnosis for cardiac } \\
\text { disease management. }\end{array}$ & [48] \\
\hline BP@lipid-PEG & Cholesterol & $\begin{array}{l}\text { Exhibit broad emissions; sharp contrast } \\
\text { and may be utilized to in situ quantify } \\
\text { the measurement of blood vessels; } \\
\text { potential in photoacoustic (PA) imaging. }\end{array}$ & [49] \\
\hline
\end{tabular}

\subsection{Modification Using Peptides}

Owing to its peculiar electrical, photonic, and mechanical characteristics, 2D black phosphorus (BP) has received the attention of the scientific community over the past few years. However, $\mathrm{BP}^{\prime}$ s inherent instability prevents its preservation and functional use. Peptides are used for molecular expression in biology and serve an important role in the development of surfaces that can recognize, react to, and eventually direct biomolecular activities at the solid-liquid interface; hence, modifying the surface of BP can overcome the abovementioned hurdles. A tailor-made tripeptide Fmoc-Lys-Lys-Phe (Fmoc-KKF) for exterior modification of BP nanosheets was synthesized in response. The BP@FKK composite exhibits exemplary stability, thereby greatly enhancing the lifespan as compared to pure BP with accelerated degradation. The BP@FKK complex also exhibited improved cellular uptake and favorable compatibility with cells due to the surface modification [42]. BP has demonstrated significant biocompatibility and immense efficiency of photothermal alteration under near-infrared light, making it quite convincing for photothermal therapy. Factual utilizations, however, are significantly hindered as BP lacks a targeting feature and readily deteriorates in cancer cells, particularly in answer to strong oxidative intracellular stress. A researcher stated that the mitochondrial targeting peptide functionalized BP nanosheets coated with an acid-labile polymer shell (doubly functional BP (DFBP) nanosheets) demonstrated exceptional stability. After surface alteration with DFBP, not only do nanosheets possess exceptional capability to accumulate in tumor tissue through surface charge switching, they could also target mitochondria, as shown in Figure 2 [43].

\subsection{Modification Using Drugs}

Black Phosphorus (BP) possesses high load carrier mobility, a configurable direct bandgap, and a distinct in-plane anisotropic framework; consequently, its applications are largely confined by the ease of $\mathrm{BP}$ oxidation into $\mathrm{P}_{\mathrm{x}} \mathrm{O}_{\mathrm{y}}$ species under ambient circumstances. In a previous study, modified cisplatin- $\mathrm{Pt}-\mathrm{NO}_{3}\left[\mathrm{Pt}-\left(\mathrm{NH}_{3}\right)_{2}\left(\mathrm{NO}_{3}\right)_{2}\right]$ was adopted for surface functionalization of BP nanosheets to produce Pt@BP (Figure 3), which preserves surface morphology and BP nanosheet properties in ambient conditions for more than $24 \mathrm{~h}$. Pt@BP displays a significant cellular uptake rate and greatly improves cisplatin-resistant cancer cell lines (A2780 and HepG2) drug response relative to unaltered cisplatin [44]. 


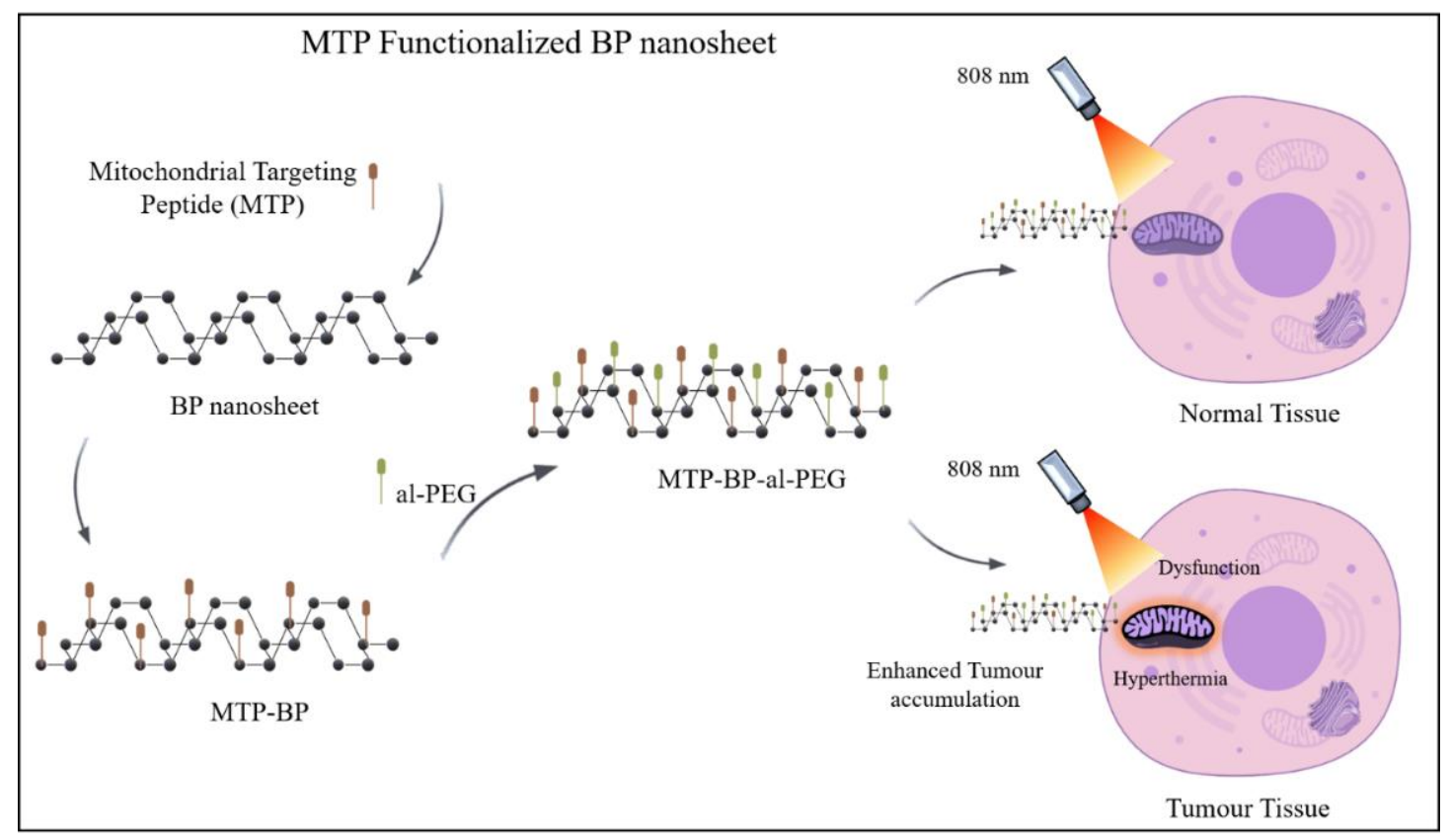

Figure 2. Mitochondrial Targeting Peptide (MTP)-functionalized BP nanosheets for enhanced tumor accumulation and mitochondria targeting.

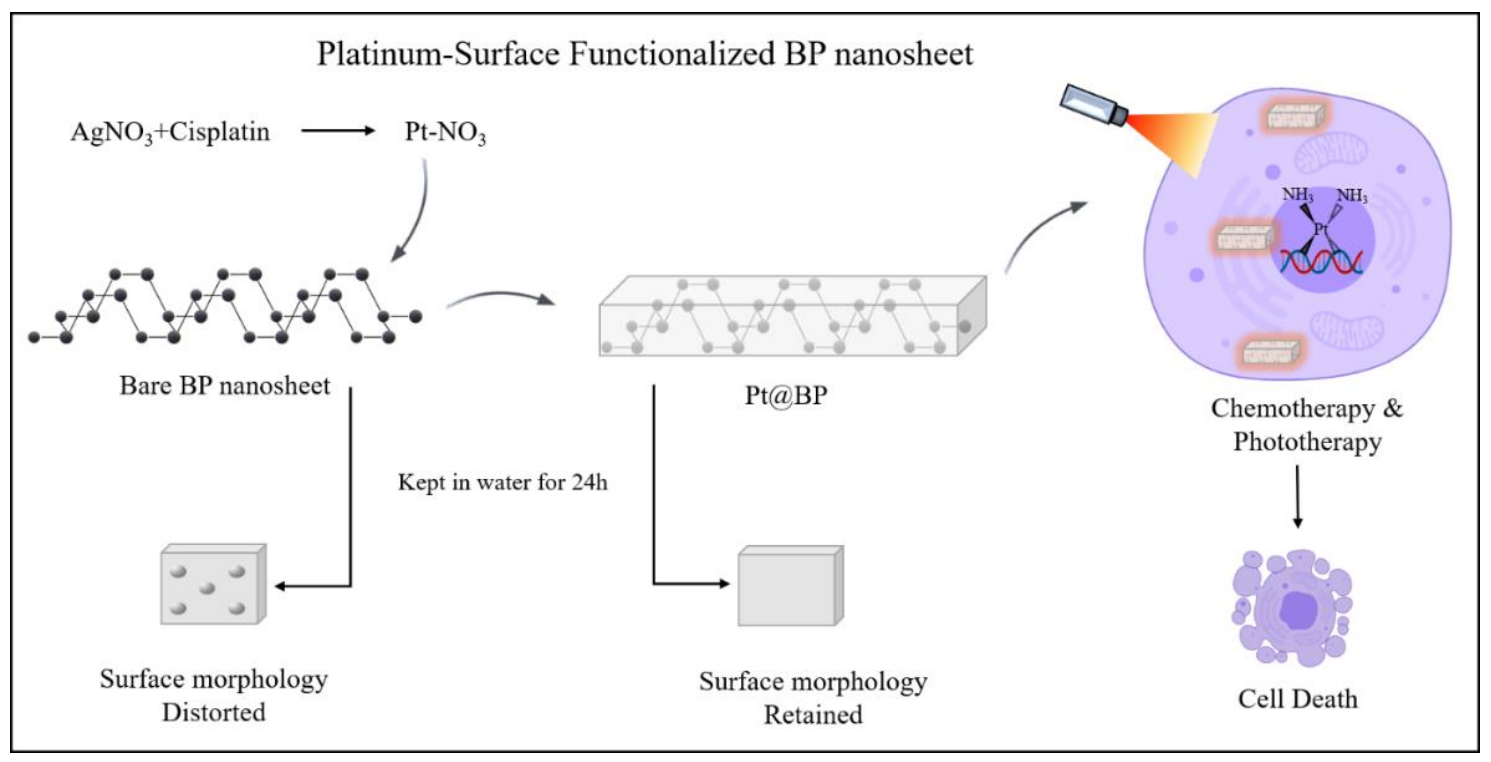

Figure 3. Modified cisplatin surface-modified BP nanosheet for synergistic chemotherapy and phototherapy.

\subsection{Modification Using Polymers}

The main drawbacks of BP are its insolubility in common organic solvents and poor airstability. This problem can best be overcome by integrating BP into a polymer framework or a polymer medium for photonic and optoelectronic applications. These modifications on BP using polymers enables the development of target specific drug delivery system and increases stability and biocompatibility. Polymer-based nanoparticles are basically developed in the biomedical field to shield guest particles or molecules from deterioration and preserve their activity [50]. Polymer modulation may decrease nanoparticle's surface energy, neutralize the surface charges, and increase the steric impedance among particles to avoid nanoparticle accumulation [51]. These properties have been shown to significantly increase the biocompatibility of BP nanomaterials including the hydrophilicity obtained from the polymeric coating [52]. Polymeric enclosures, on the other hand, can minimize 
the interaction of BP nanomaterials with water and oxygen and thereby efficiently reduce the degradation by oxidation [53,54]. In this segment, we discuss the various polymeric surface modification approaches on BP nanomaterials. In one study, BP quantum dots (BPQDs) were manufactured utilizing a liquid exfoliation approach which was coupled with sonic probe and bath sonication. The BPQDs displayed increased stability in the physiological medium after PEG conjugation, and no apparent toxicity was identified for different cell types [45]. In similar research, BPQDs were fabricated and functionalized by targeting moieties of folic acid linked with PEG-diamine (PEG-NH2-FA), for photodynamic-photothermal-chemotherapy by loading with anticancer drug (doxorubicin). Using PEG@BPQD@DOX, 5 min of NIR irradiation significantly raised the temperature of the tumor site to $44.2^{\circ} \mathrm{C}$ since PEG-coated nontargeting NPs did not target tumor sections efficiently. Furthermore, after $4 \mathrm{~h}$ and an FA-PEG@BPQD@DOX intravenous (IV) injection, the temperature at the tumor section rose speedily along with the period of irradiation. The irradiation of $300 \mathrm{~s}$ at $808 \mathrm{~nm}\left(2 \mathrm{~W} / \mathrm{cm}^{2}\right)$ speedily increased the temperature to $56.8^{\circ} \mathrm{C}$, which is enough to destroy human embryonic kidney (HEK 293T) cancer cells [46]. In another approach, BP was coated with polydopamine (PDA) and a novel nanocapsule BP@PDA-PEG-FA loaded with doxorubicin (DOX) as a classical drug for cervical cancer treatment was prepared, and configured with mercapto group (HS)-based targeting polymer, HS-PEG-FA. This drug delivery system based on BP demonstrated improved stability, significantly higher photothermal performance, and the capability to kill cancer cells. In addition, DOX was released in a low $\mathrm{pH}$ microenvironment of tumor under NIR laser irradiation, showing the impact of synergistic therapy [47].

\subsection{Modification Using Aptamers and Antibodies}

Apart from protection, surface modifications may also enhance BP's biosensing properties and thus lead to its probable use in biomedical applications. Aptamers show a peculiar binding to their respective target molecule based on their particular three-dimensional framework, which may be a small molecule, a macromolecule, or an entire cell. Aptamers can be utilized for surface modification of BP because of their high precision and high affinity. Poly-L-lysine (PLL)-coated BP nanosheets (BPNSs) enabled the functionalization of BP with anti-Mb aptamer (PLL-BP-Apt) that could be used as electrodes to identify cardiac biomarker myoglobin $(\mathrm{Mb})$ in serum samples by means of electrochemical detection procedures, as depicted in Figure 4 [48]. In another study, electrochemical detection of circulating tumor cells (CTCs) was reported using a probe of BP@AuNPs@aptamer coupled with immuno-magnetic separation. Aptamers can precisely bind to CTCs, whereas the aptamers along with the phosphorus oxides, such as phosphate and phosphite ion (PxOy species) on BP, can react with molybdate to produce an electrochemical current, resulting in dual signal amplification. [55]. A bio-inspired structural vesicle was developed by attaching osteoblast targeting aptamers to the poly D,L-lactic-co-glycolic acid (PLGA), which further surrounded and guided the BPQDs to actively target cells. To upregulate the development of heat shock proteins and alkaline phosphatase, which synergized with deteriorated inorganic phosphates in efficient biomineralization for bone regeneration, the photothermal activity of the BPQDs was effectively explored [56]. A nominally invasive therapeutic IV catheter was developed in another study for the photothermal destruction of CTC. The catheter cavity was filled with nanosheets of BP and the layer was modified using anti-EpCAM antibody. The catheter continuously captured CTCs in the peripheral blood with the help of circulatory system and the trapped CTCs were employed downstream or eliminated in vivo by NIR-induced photothermal effect of the BPNSs [57]. 


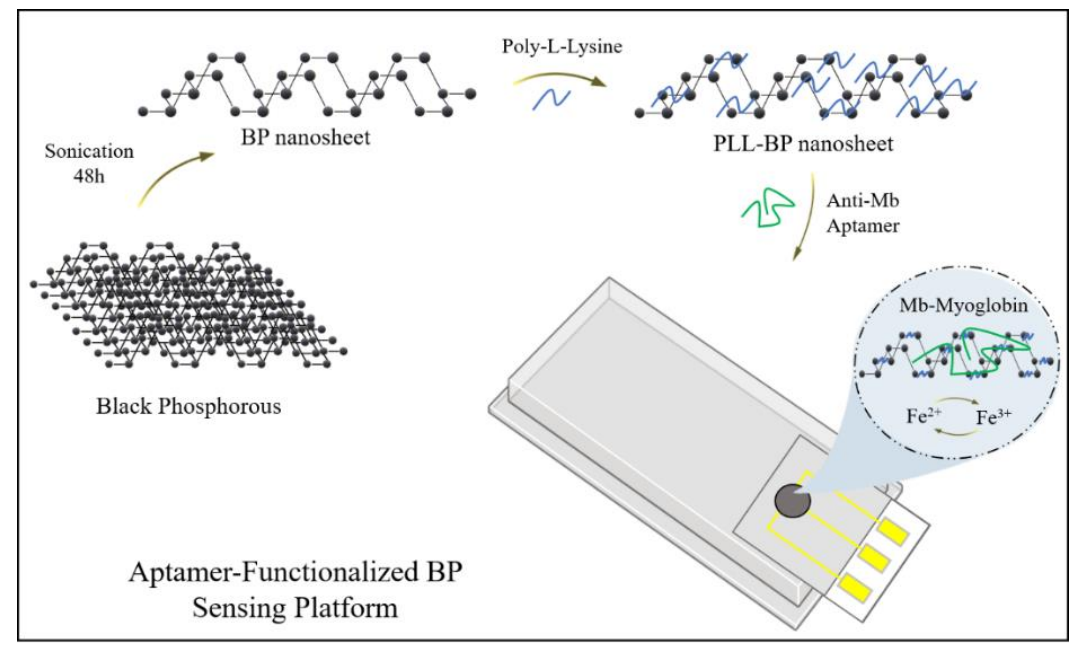

Figure 4. Aptamer-functionalized BP sensing platform for detection of Myoglobin.

\subsection{Modification Using Lipids}

Most of the inorganic materials have the limitation of a rough surface with sharp edges, which can affect cellular organelles during interactions. Similar reports have been published for graphene oxide whose sharp edges have been reported to damage blood cells. To overcome this problem, surface modification was carried out which not only helped make the surface smooth, but also enhanced the biocompatibility of inorganic materials. In the case of BP, although very scarce literature has been published for surface modification using lipids, the available literature suggests the possible enhancement in inherent properties such as fluorescence, in addition to biocompatibility. In a recently published report, it was found that lipid modifications demonstrate intense NIR-II fluorescence and could be embedded with the PEGylated cholesterol (BP@lipid-PEG nanospheres) for both in vivo and in vitro NIR-II imaging [49]. The subsequent nanospheres displayed broad emissions by an $808 \mathrm{~nm}$ laser under excitation from 900 to $1650 \mathrm{~nm}$ and had a quantum yield of $8 \%$ of that of the standard reference dye, IR-26.

\section{Characterizations Techniques for BP}

The fundamental properties of BP can be identified and exploited by several characterization techniques. For instance, UV-Vis spectroscopy can be employed to record the absorption spectra of BP at an excitation wavelength ranging from 290 to $450 \mathrm{~nm}$. Raman spectroscopy aids in finding the sample purity upon irradiation by a visible laser beam with a $514 \mathrm{~nm}$ wavelength and also serves as an efficient method to detail the vibrational and rotational modes of the sample which in turn describes its morphology [13]. A spectrofluorometer provides the information about the internal quantum yield by excitation and emission wavelengths of $370 \mathrm{~nm}$ and 380-700 nm, respectively. Scanning transmission electron microscopy confirms the exfoliated structure of BP by resolving the atomic structure with a precise resolution of $2 \AA$. Hence, in the following section, we describe a few techniques employed in characterizing the BP nanosheets in detail.

\subsection{Spectroscopic Techniques}

Several spectroscopic techniques, such as infrared spectroscopy, X-ray photon spectroscopy, polarization-dependent spectroscopy, and photoluminescence (PL), are employed in characterizing BP. These techniques help in the understanding of representative vibrational modes, crystallinity, crystallographic directions, and intrinsic bonding energies. External stimuli such as temperature, strain and pressure are used to explore the inherent anisotropic properties which arise because of the specific puckered structure of black phosphorous [58]. The spatial inhomogeneity of phosphorene is of specific interest because of its puckered structure; in addition, the strain can alter properties such as mechanical 
and chemical properties. Near field Raman or confocal Raman scattering offers higher resolution in the spatial strain distribution. Photoluminescence (PL) often depends on the BP energy band. Semiconductors can adsorb photons with adequate energy that leads to several pairs of electron-holes on the surface of materials-this is called intrinsic absorption. Such extra carriers will disperse and recombine as soon as possible into the inner region of the semiconductors. This generates photons in the recombination [59].

PL calculation is, therefore, an important method for measuring the structure of the band. The PL peak position differs according to BP thickness. When the exciting laser's polarization and the polarizer's linear polarization are parallel and align with the orientation of the armchair (x-axis), the photoluminescence intensity will reach its maximum. In addition, the PL strength is strongly reliant upon the extinction ratio [60]. If the polarization of the detector is in a zigzag path, the intensity drops significantlythat is, less than $3 \%$ in the direction of the armchair, irrespective of the exciting light's polarization. These unusual anisotropic characteristics distinguishes the BP dramatically from other 2D materials and can shed some light on the dynamics of the carrier and the band structure [60]. The PL spectroscopy of BP was performed by Zhang and team on a silicon substrate. Stronger PL peaks were observed at 1558, 1413, 1268, and $961 \mathrm{~nm}$, in 5-, 4-, 3- and 2-layered flakes, which correspond to the energy peaks of $0.8,0.88,0.98$, and $1.29 \mathrm{eV}$, respectively [33]. These PL peaks demonstrated the nature of extinctions, representing the lower bond on the primary band gap values present in few-layer BP. The position of energy in the measured peaks increases with the decrease in number of layers and indirectly denotes that, with the decrease in layer number, the band gap of few-layer $\mathrm{BP}$ increases, which may be attributed to the smaller band dispersions of the conduction band and valence band related to the weaker interlayer interaction [61]. Another study reported the PL of BP upon excitation with a green laser and the results showed that with increase in number of layers the intensity of the PL peak decreased, indicating a decrease in optical bandgap [62].

\subsection{Thermal Techniques}

Understanding the thermal properties of few-layer or single-layered BP is of particular interest for fundamental research and its applicability. From the research perspective, it is important to know the conduction of heat in low-dimensional materials to obtain a better picture of thermal management and heat dissipation at the nanoscale [63]. Phonons (vibrations of crystal lattice) function as the primary heat carriers in insulators and semiconductors. This phenomenon of phonon conduction in nanowires and films differs from the bulk and is suppressed because of the changes in phonon density, dispersion, and boundary scattering. So, the possibility of controlling the phonon at the nanoscale has led to the application of nanomaterials in thermoelectrics [64]. Although the melting point (M.P.) of bulk black phosphorous ranges between 600 and $1000{ }^{\circ} \mathrm{C}$ [65], the precise M.P. for a fewlayer BP remains under consideration. The information of BP's linear thermal expansion coefficients (LTECs) seems to be of great importance in terms of 2D materials, to acquire a better and deeper understanding of its anisotropic thermal properties. Presently, there are very few techniques to measure the thermal conductivity of BP. Temperature-dependent Raman scattering was performed by a research team [66] and the results showed that the temperature coefficient of BP thin films decreased with decreasing thickness. In addition, the suspended state BP showed thermal conductivity of $15.8 \mathrm{~W} / \mathrm{mK}$ and it increased to $29.2 \mathrm{~W} / \mathrm{mK}$ when supported on silica substrate. This indicates that the properties of BP films can be significantly affected by the substrate and the extent of this varies based on the property of the specific material of a given thickness. Jeon et al. experimentally and theoretically explored thickness influences on the thermal conductivities of BP nanosheets for an extensive temperature range of 100 to $300 \mathrm{~K}$ [67]. Henry et al. recently reported precise measurements of thermal expansion along the three crystallographic axes, using X-ray diffraction in situ at high temperatures [68]. Another group of researchers utilized micro-Raman spectroscopy to study the thermal conductivity of BP films and found that 
the anisotropic ratio for thick films was $\sim 2$ and dropped down to $\sim 1.5$ for the thinnest film, which had a thickness of $9.5 \mathrm{~nm}$. This can be ascribed to the anisotropic phonon dispersion. The advantage of using this method is that it allows for simultaneous probing to record temperature as well as for local heating of the thin film sample. However, difficult automation and uncertainty of beam size are limitations $[69,70]$. Hence, there is a need for reliable experimentation and systematic comparison between the measurements and theoretical predictions to understand the underlying physics in a better way.

\subsection{Optical Techniques}

2D materials show a good optical response in a third order nonlinearity with a broad bandwidth, a miniature size, and an ultrafast response. Hence, they are suitable for optical light processing operations [71]. The same as photon radiation, the intrinsic essence of optical absorption includes an interaction between an electron and a photon usually occurring at edges of the band. As stated by Fermi's golden rule, this process has a higher probability of occurring in two energy states having a higher combined density of states [72]. Optical properties (OPs) rely primarily on different factors, such as Raman scattering (RS), optical absorption, and BP photoluminescence [60]. BP's optical absorption has been extensively researched both by theoretical and experimental measurements $[30,60,73]$. BP's direct bandgap lies between graphene and transition metal dichalcogenides, and thus, it serves as an ideal material for several optical applications. The BP bandgap depends heavily on the number of layers. Therefore, the size of the respective photoabsorption often varies according to the thickness of BP flakes.

Raman spectroscopy is a robust, nondestructive tool often used for characterizing the nanoparticles to determine the thickness [74], strain [75], and angle [76] of the nanomaterials. Based on the group theory and conservation of momentum, BP consists of six Raman active modes. However, when the incident laser falls perpendicularly to the layers of phosphorene, only three modes can be identified, which are $\mathrm{A}^{1} \mathrm{~g}_{\mathrm{g}} \mathrm{A}^{2} \mathrm{~g}$, and $\mathrm{B}_{2 \mathrm{~g}}$ phonon modes corresponding to the 362,467 , and $439 \mathrm{~cm}^{-1}$ wavelengths, respectively [62]. When the temperature rises from 78 to $573 \mathrm{~K}$, softening occurs in these modes [77]. With the increase in number of layers, Raman peaks red-shifted, indicating the hinderance of phonon vibration with the addition of new layer to the surface of BP [78]. Further, based on optical anisotropy, the crystalline orientation of BP can be identified using polarized (angle resolved) Raman spectroscopy [76]. It was observed that by rotating an arbitrarily located sample under the parallel polarization configuration, the intensity of the $\mathrm{A}^{2} \mathrm{~g}$ band increased when the orientation of armchair was along the polarization path of scattered light. Anisotropic Raman spectroscopy also finds an application in measuring the degree of strain on BP samples [71,75]. The Raman scattering of BP displays that the thickness of BP layers can be identified by the low-frequency interlayer Raman modes. As described by the optical transition selection rule, each interaction can have different anisotropies. Thus, using the multiple characterization techniques, the optical characterization provides an efficient platform to understand the physics of materials.

\subsection{Electron Microscopic Techniques}

Electron microscopy offers enhanced magnification and resolution for the visualization of biological and nonbiological samples and understanding their structural organization. Transmission electron microscopes (TEMs) function by transmitting the beam of electrons through the sample generating a projected image, while the scanning electron microscope (SEM) scans the surface of the sample with the aid of a focused electron beam, which renders the emission of particles from the surface forming an image $[79,80]$. Generally, electrons with short wavelengths are used as a source of illuminating radiation. The same as other nanoplatforms, BP can also be surface characterized using these electron microscopic techniques. It shows a puckered hexagonal ring in the orthorhombic crystal structure and, as described earlier, the individual layers are held together by van der Waals forces. TEM images of a single layer of BP are shown in Figure 5 [81]. For instance, BP quantum 
dots (BPQDs), when analyzed through TEM, demonstrated the lattice fringes of $0.34 \mathrm{~nm}$ attributable to the (021) plane of the BP and the statistical analysis of the obtained TEM analysis revealed that the average size and thicknesses of the BPQDs were $2.6 \pm 1.8 \mathrm{~nm}$ and $1.5 \pm 0.6 \mathrm{~nm}$, respectively [45]. Another study employed SEM to analyze the cell viability of osteo-sarcoma derived (SAOS-2) cells and healthy osteoblast cells (HObs) upon incubation with the exfoliated BP. The initial morphologies of the SAOS-2 cells were replaced by the shape of typical apoptotic cells, while the images of $\mathrm{HOb}$ cells exhibited polygonal morphologies and good cell spreading of the differentiating cells [82]. Similarly, FLBP nanosheets fabricated using the liquid exfoliation method were subjected to TEM analysis by drop-casting the exfoliated FLBP suspension on a carbon grid. TEM images showed that the nanosheets possessed an average lateral length of $2.1 \mathrm{~mm}$ and thickness of around $8 \mathrm{~nm}$ [83].
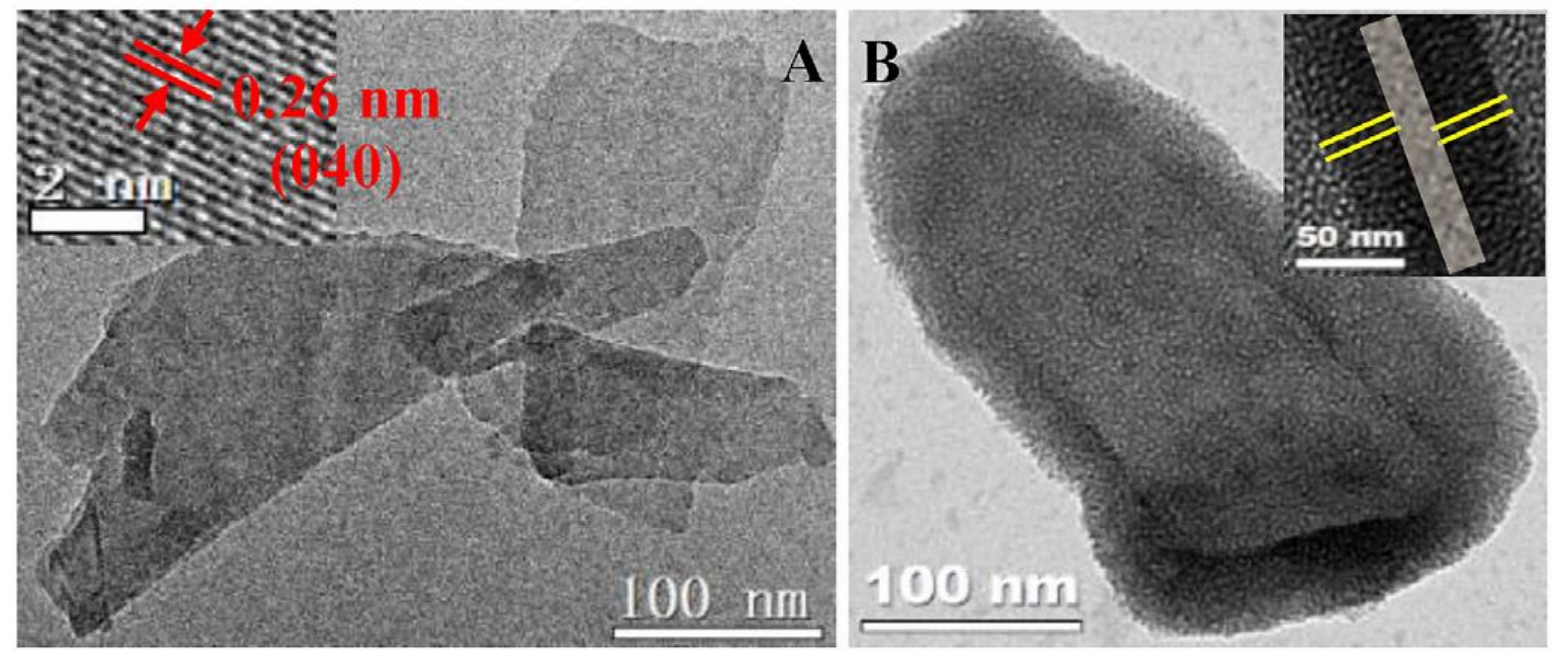

Figure 5. TEM image of (A) pristine BP nanosheet, and (B) BP@MS (Mesoporous silica). Reproduced with permission from [81]; Copyright Elsevier, 2020.

\subsection{Plasma-Protein Adsorption Study}

The adsorption of proteins on the surface of nanoparticles when they come in contact with the protein rich environment plays a vital role in deciding the fate of NPs. Several studies have described the role of protein adsorption in biological interactions [84] and have stated that "Protein corona" refers to the spontaneous self-assembly or biomolecular coating of the proteins on the surface of nanoparticles [85]. The formation of corona not only alters the physical properties of the nanomaterials such as size, surface charge, shape but also alerts the immune system of the body to recognize the nanoparticles as an intruder and hastens the process of opsonization [86]. Having said that, it becomes important to identify various characterization techniques to detect the extent of protein corona formation. Though several techniques such as quantitative and qualitative proteomic assays have been described to characterize the protein corona formation of the nanoparticles [87], very few studies have reported on its formation around BP nanomaterials. Here, we have discussed the techniques available to characterize the formation of protein corona around the BP nanomaterials.

Electron microscopies, such as TEM, provide a clear picture of protein corona formation around the nanoparticles. For instance, in a previous study [88], the size of BPNSs was increased by $11.9 \mathrm{~nm}$ after being covered by plasma proteins and, in another study, the size increased by $30 \mathrm{~nm}$ [89]. The corona formation can also be detected by a change in surface charge. The surfaces of BPNSs coated with plasma proteins were entirely different from the native form and the charge changed to a positive value from negative. Liquid chromatography with a mass spectrometry detector was used to qualitatively analyze the components of the BP-corona complex. The results revealed that the binding of proteins 
to BP directly depends on the protein size and, additionally, the BPNSs mainly bind with immune relevant proteins. The composition of the protein corona can also be evaluated using Sodium dodecyl sulfate-polyacrylamide gel electrophoresis (SDS-PAGE). The strength of the bands in electrophoresis was examined by relative densitometry and the results demonstrated that the intensity of bands increased with the increase in protein concentration [90]. The outcomes of dynamic light scattering studies showed that protein corona formation increased the size of BPNSs by approximately $30 \mathrm{~nm}$ and the ultrasmall BPQDs were redefined to bulky spherical QDs after protein corona formation.

Elemental dispersive spectroscopy can also serve as a prominent method to characterize the formation of a protein coat around BP nanomaterials. The increase in the intensity of C, P, and N indicate the formation of corona $[88,89]$. Further, a real-time polymerase chain reaction can be used to understand if the $\mathrm{BP}$ nanomaterials induce the M1 macrophages. When BPNSs were exposed to the macrophages, there was an upregulation in the M1related markers such as interleukins and CD16. With the enrichment of immune proteins, the uptake of the BP-corona complex by macrophages increases, and this, in turn, enhances the immune perturbation in the macrophages, while the expression of M2-related genes, such as IL-10 and CD206, Z decreased. These data help the researchers to understand the process of protein corona formation and its role in deciding the biological activity of BP nanomaterials and thus enable them to design safe and effective BP nanoplatforms.

\section{Biomedical Applications of Black Phosphorus}

\subsection{Application in Drug Delivery}

$\mathrm{BP}$, also known as phosphorene, has drawn significant interest in therapeutics and drug delivery amongst the 2D class of inorganic nanomaterials [91]. The puckered orthorhombic configuration provides BP with a high surface to volume ratio, thus increasing the drug loading capacity [92]. Because of phosphoric acid, the surface of BP is negatively charged and can thus encapsulate positively charged drug molecules or nanoparticles by electrostatic interactions within the interlayer spaces [93,94]. The use of BP in drug delivery varies from bone therapy (owing to the inclusion of a phosphorus atom that is an integral part of the bone) [95], cancer therapy (high surface area and photosensitive characteristics) [96], wound healing (superior photothermal agent and oxygen carriers) [97], neurodegenerative disease (antioxidants and enhanced BBB permeability owing to BP's photothermal properties) [7], and implants [98]. The following section describes the application of BP in drug delivery.

\subsubsection{Bone Therapy}

Bone regeneration is a significant challenge in clinical surgery due to various conditions such as osteomyelitis, osteitis, traumas, and tumors [99]. In the past, several therapeutic strategies (autographs and allografts) have been implemented, with autographs being the gold standard of clinical practice. However, this suffers from certain disadvantages such as damage to the donor site, reduced bone mass and size, low availability, and the fact that it can induce immune responses and transmit disease [100]. Hence, with the advancements in tissue engineering, synthetic bone replacement materials have become the primary study in the field of bone regeneration [101]. On comparison with autografts, synthetic bone materials pose several advantages such as bone targeting, drug delivery carriers [102], ease of synthesis [103], and ease of functional modifications [104].

Phosphorus $(\mathrm{P})$ is a key element of the body responsible for bone regeneration and for maintaining a bone's mechanical strength [105]. It accounts for approx. $1 \%$ of the overall body mass [106], $85 \%$ of which is found in the form of hydroxyapatite in the bones and teeth [107]. Numerous studies have shown that materials rich in phosphate can promote mineralization and promote bone regeneration [108]. BP-based nanomaterials have substantial benefits in bone therapy due to the single $\mathrm{P}$ element that generates nontoxic $\mathrm{PO}_{4}{ }^{3-}$ when degraded in ambient conditions [109], which is a source for remineralization that can promote in situ bone regeneration by trapping the surrounding $\mathrm{Ca}^{2+}$ ions by 
forming calcium phosphate [110]. Another advantage is that the photosensitive nature of BP in NIR allows the release of entrapped drugs in a controlled manner for a longer duration. Moreover, few studies have shown that BP's photothermal property tends to upregulate markers-i.e., alkaline phosphatase [45] and heat shock protein [111] - that are responsible for accelerating bone growth. BP 2D nanosheet scaffolds, hydrogels, and microspheres have been employed in bone regeneration. In a study, porous Gelatin methacryloyl (GelMA) hydrogel-based BP nanosheets (BPNS) (previously synthesized by liquid exfoliation) were fabricated to promote the release of phosphate ions in a controlled manner and trap the surrounding $\mathrm{Ca}^{2+}$ ions to facilitate bone regeneration. In vitro and in vivo experiments (rabbit model) were performed to recognize the photoresponsive phosphate release activity and to determine the efficiency of bone regeneration. The findings showed that BPNS hydrogel release $\mathrm{P}$ in a photoresponsive and controlled manner, speeding the process of in vitro mineralization. In addition, the in vitro osteogenic differentiation results also showed that the BPNS hydrogel improved osteogenic differentiation of stem cells via the BMP-RUNX2 pathway. The in vivo studies revealed that when the BPNS hydrogel was used, bone recovery was possible within 12 weeks [95]. Similarly, Miao et al. synthesized BPNS via a liquid-phase stripping method and integrated it onto GelMA hydrogel to form BP/Gel nanocomposites and explored its activity on bone regeneration. The in vitro experiments have shown that incorporating BPNS into the hydrogel matrix promotes biomineralization, which was confirmed by quantifying $\mathrm{P}, \mathrm{O}$, and Ca elements by SEM equipped with energy dispersive $X$-ray spectroscopy. Furthermore, staining with Alizarin red S staining verified that the nanocomposite could facilitate osteogenic differentiation of hMSCs. To study the in vivo bone regeneration using BPNS hydrogel composites, a rat cranium defect model was used. Bone growth was being observed to advance from the periphery to the center in 9 weeks, thus illustrating the in situ development of bone [112]. In a study, a thermo-responsive hydrogel was constructed by incorporating BPNS into a chitosan polymer with platelet rich plasma for phototherapy of rheumatoid arthritis (RA). The Photodynamic Therapy (PDT) and Photothermal Therapy (PTT) properties of BPNS could excise the hyperplastic synovial tissue and eventually promote in situ biomineralization. In addition, a delayed drug release of methotrexate was also detected, indicating synergistic effects in the treatment of RA and stimulation of bone growth [54].

Matrix vesicles (MVs) derived from extracellular vesicles, which are primarily responsible for building the extracellular matrix and controlling the physiological activities of cells, were responsible for bone mineralization. In a study, similar concept was used where, aptamer-modified MVs were designed for in vivo bone regeneration and biodegradable BPQDs served as a source for inorganic phosphate and MVs to direct the complex to the desired region in the bone [56]. In a previous study, BP and strontium chloride were embedded into poly D,L-lactic-co-glycolic acid (PLGA) microspheres that were synthesized by an $\mathrm{o} / \mathrm{w}$ emulsion solvent evaporation technique for bone regeneration, as shown in Figure 6. The excellent PTT effect of BP assisted NIR irradiation led to the controlled release of $\mathrm{Sr}^{2+}$ by penetrating the PLGA shell. In vivo results on the rat femoral defect model by implanting the BP microspheres showed enhanced bone regeneration compared to plain microspheres or without NIR irradiation [113]. In bone regeneration therapy, BP-based nanomaterials have demonstrated satisfactory outcomes relative to other $2 \mathrm{D}$ nanomaterials. However, some problems, such as low stability and unpredictable immune responses, are yet to be addressed. 


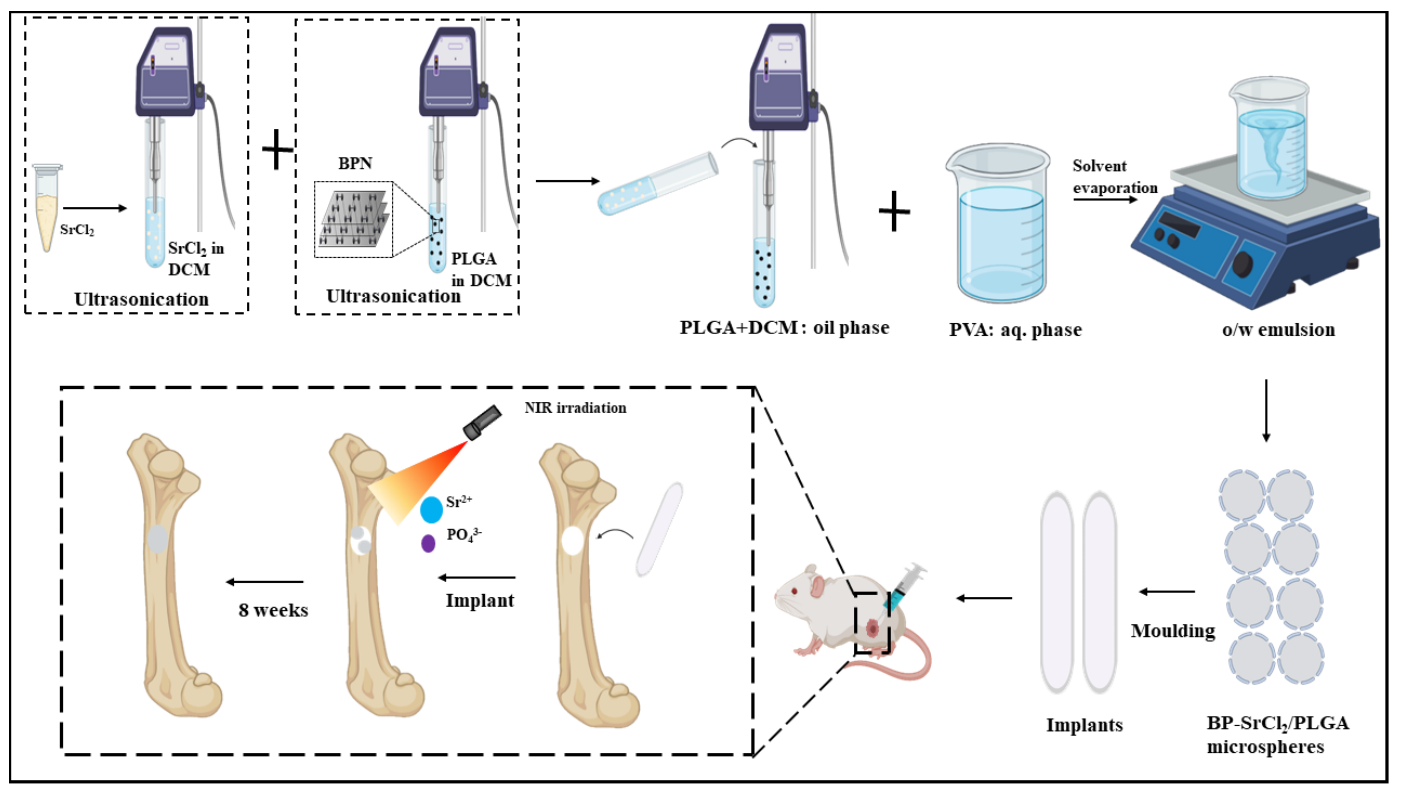

Figure 6. Schematic representation of $\mathrm{BP}-\mathrm{SrCl}_{2} /$ poly D,L-lactic-co-glycolic acid (PLGA) synthesis and its therapeutic application in bone regeneration.

\subsubsection{Cancer Therapy}

The novel application of 2D metallic nanomaterials as nanocarriers in multimodal nanomedicine is being thoroughly investigated as an alternative to conventional cancer therapy due to their exceptional physicochemical properties. BP has received significant research interest among the different types of 2D metallic nanomaterials due to its unique characteristics [114]. For example, BP metallic nanocomposites offer great potential as photothermal agents for PTT (due to the high photothermal conversion) [115] and PDT (good photosensitizers due to generation of reactive oxygen species) [92,116], drug delivery (because of its high surface area, biocompatibility, and biodegradability) [117], and multimodal theranostic agent in cancer therapy [118].

NIR irradiation-mediated hyperthermia due to the presence of photothermal absorbing agents is the mechanism in photothermal therapy to eradicate tumors [119]. The photothermal conversion efficiency and high extinction coefficient of BPs make them better candidates in photothermal therapy [120]. In a study, a sprayable BPNS incorporated within a thermosensitive and biodegradable hydrogel was utilized for postsurgical treatment of cancer. The BPNs were fabricated by a modified liquid exfoliation method and further incorporated in the Poly(d,l-lactide)-poly(ethylene glycol)-poly(d,l-lactide (PLEL) hydrogel by ultrasonication in 30\% w/v PLEL solution. On application of a small amount of hydrogel on the tumor site, rapid conversion of sol-gel occurs with NIR irradiation $(808 \mathrm{~nm})$ and the high PTT efficacy helps to efficiently eradicate tumor tissues, which was evident in the in vivo and in vitro studies. The biocompatible nature of the BP@PLEL hydrogel was evident upon incubation with several cancer cell lines which demonstrated that cytotoxicity and similar results were observed in vivo; hence, they concluded that the nanocomposite not only eliminates the tumor, but also assists in wound healing and has significant therapeutic potential in cancer therapy [121]. To prevent degradation of BPNS in ambient conditions, Li et al. modified its surface with 1-pyrenylbutyric acid and conjugated with RGD peptide for targeted PTT therapy (Figure 7). The RP-p-BPNS was fabricated by a simple liquid exfoliation method and the fabricated RP-p-BPNS exhibited excellent biocompatibility and good stability in an ambient environment (7 days) with carboxyl groups available at its surface for conjugation with an RGD peptide (EDC-NHS chemistry) for enhanced tumor targeting. P-BPNS showed a significant cytotoxicity effect on the cancer cell under NIR irradiation at $808 \mathrm{~nm}$ due to the specific binding of the RGD peptide and $\alpha_{\mathrm{V}} \beta_{3}$ ligands present on the surface of the cell membrane, thereby increasing 
the intracellular concentration of p-BPNS in the cancer cells. Similar findings were obtained in in vivo studies of tumor-bearing nude mice in which complete tumor suppression was observed in the p-BPN-treated group in comparison with the controlled group, suggesting that the PTT effect of BPNS was further amplified by RGD conjugation [122]. In a recent publication, BP's PTT potential was explored by synthesizing BPNS gold nanoparticles (Au-BPNS) using a simple one-step synthesis. The experimental findings showed that, upon irradiation with $808 \mathrm{~nm}$ laser, Au-BPNS showed an excellent antitumor effect in the NIR region compared with bare BP. Studies have also shown that Au-BPNS could be utilized as an efficient surface-enhanced Raman scattering (SERS) matrix for Raman biodetection [123].

In addition to BP phototherapy, chemotherapy was found to be effective wherein BP appeared to have chemotherapeutic effects and could also be loaded with several molecules for enhanced chemotherapeutic activity [124]. Several papers report the use of combinatorial therapy that includes PTT/chemotherapy, PTT/gene/chemotherapy, and PTT/PDT/chemotherapy, as shown in Table 3.

Using a modified liquid exfoliation technique, Wan and colleagues developed BPNS and coated it with PEG through electrostatic deposition. In order to boost immunotherapy, BPNS was integrated with R837. In the presence of NIR (808 nm), the developed PEGBPNS displayed excellent photothermal stability and high photothermal efficiency, thereby inhibiting B16 cells (murine melanoma cell lines). Compared to bare BP, the synergistic effect of PTT generated tumor antigens and R837-mediated activation of antigen-presenting cells caused a significantly greater response [125]. The high ROS generation capability of BPNS makes them effective photosensitizer agents and ideal candidates in PDT. In a previous study, a novel nanocomposite (BP@Au@ $@ \mathrm{Fe}_{3} \mathrm{O}_{4}$ ) was fabricated by depositing $\mathrm{Au}$ and $\mathrm{Fe}_{2} \mathrm{O}_{3}$ nanoparticles on BPNS using a single-step electrostatic attraction method. The BPNs were synthesized using a liquid exfoliation in deionized water for $8 \mathrm{~h}$. The $\mathrm{BP} @ \mathrm{Au} @ \mathrm{Fe}_{3} \mathrm{O}_{4}$ showed good antitumor activity due to synergistic activity displayed by both $\mathrm{Au}$ (PTT and PDT at $650 \mathrm{~nm}$ ) and $\mathrm{Fe}_{2} \mathrm{O}_{3}$ (tumor targeting and magnetic resonance imaging). The MTT assay was used to confirm the noncytotoxic effect of the prepared nanocomposite in HeLa cells thereby exhibiting good biocompatibility. The in vivo results proved the antitumor efficiency of the nanocomposites [126]. Hence, several studies proved BP efficacy as a PTT, PDT, and chemotherapeutic agent in cancer therapy [53,126-131].

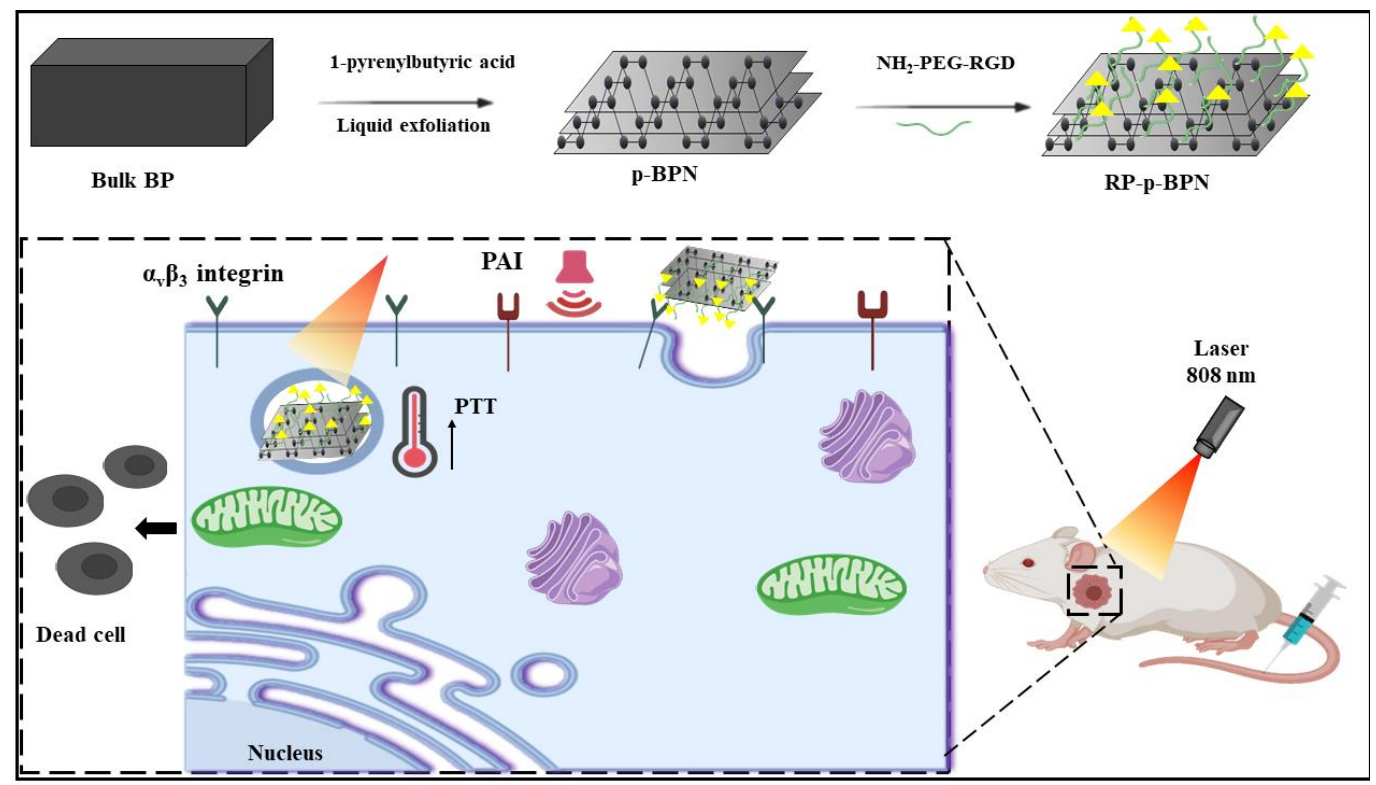

Figure 7. Schematic representation of red phosphorus (RP)-p-Poly-L-lysine (PLL)-coated BP nanosheet (BPNS) synthesis and its therapeutic application in cancer imaging and therapy. 
Table 3. Summary of applications of BP in therapy of cancer.

\begin{tabular}{|c|c|c|c|c|c|}
\hline Nanocomposite Material & Application & Synthesis of BPNS/BPQD & Cancer type/Cell Lines & Research Outcome & Reference \\
\hline BPNS & PDT & Liquid-phase exfoliation & MDA-MB-231 cells & $\begin{array}{l}\text { BPNS inhibited tumor growth with short } \\
\text { exposure of light irradiation due to effective } \\
\text { photosensing efficiency }\end{array}$ & [92] \\
\hline $\begin{array}{l}\text { BP Quantum Dots Resealed } \\
\text { erythrocyte nanovesicle } \\
\text { (BPQD@RM) }\end{array}$ & PTT/Immunotherapy & Sonication exfoliation & 4T1-breast tumor cells & $\begin{array}{l}\text { The combination of PTT with programmed cell } \\
\text { death protein delayed the metastatic growth } \\
\text { in vivo by increasing activity of CD } 8+\mathrm{T} \text { cells } \\
\text { activity in tumor }\end{array}$ & [132] \\
\hline BPNS cellulose hydrogels & PTT & Liquid-phase exfoliation & $\begin{array}{l}\text { SMMC-7721 hepatocellular cancer } \\
\text { cell lines }\end{array}$ & $\begin{array}{l}\text { The BPNS hydrogel composites displayed } \\
\text { excellent PTT efficiency against cancer and was } \\
\text { also biocompatible }\end{array}$ & [133] \\
\hline PEGylated BPQD & $\mathrm{PDT} / \mathrm{PTT}$ & Sonication exfoliation & Hep G2 cells & $\begin{array}{c}\text { The PEGylated BPQDs showed strong NIR } \\
\text { absorption to generate ROS and inhibit tumor } \\
\text { thereby showing a theranostic activity in cancer } \\
\text { therapy }\end{array}$ & [118] \\
\hline $\mathrm{BPN} / \mathrm{MnO}_{2}$ & PDT/PTT/Gene therapy & $\begin{array}{l}\text { Modified Liquid-phase } \\
\quad \text { exfoliation }\end{array}$ & HeLa and A549 lung cancer cells & $\begin{array}{l}\text { Combinatorial therapy resulted in the release of } \\
\text { siRNA to targeted tumor cells by specific } \\
\text { nanocomposite degradation and ROS produced } \\
\text { by irradiation, led to the suppression of tumor } \\
\text { growth. }\end{array}$ & [134] \\
\hline $\begin{array}{c}\text { PDA@BPQD } \\
\text { (Polydopamine functionalized } \\
\text { BPQDs) }\end{array}$ & $\begin{array}{c}\text { Photoacoustic imaging (PAI) } \\
\text { PAI/PTT }\end{array}$ & Sonication exfoliation & $\begin{array}{l}\text { Nude mice bearing A375 human } \\
\text { melanoma tumor }\end{array}$ & $\begin{array}{l}\text { Along with the stability, PDA@BPQDs } \\
\text { possessed good photothermal performance on } \\
\text { cancer cells }\end{array}$ & [135] \\
\hline $\begin{array}{l}\text { BPN-CuS-FA } \\
\text { (Folic acid anchored CuS } \\
\text { nanodot-modified BPN) }\end{array}$ & $\mathrm{PDT} / \mathrm{PTT} / \mathrm{PAI}$ & $\begin{array}{l}\text { Modified mechanical } \\
\text { exfoliation }\end{array}$ & 4T1-breast tumor cells & $\begin{array}{l}\text { BPN-CuS-FA displayed good PAI activity, } \\
\text { enabling in vivo monitoring. The FA targeted } \\
\text { folate receptors on the tumor cells enabled the } \\
\text { uptake of BPN-CuS complex which showed } \\
\text { PDT-PTT-mediated antitumor activity }\end{array}$ & [136] \\
\hline $\begin{array}{l}\text { PEG@BPN-Ce6 } \\
\text { (Chlorin e6 BPN) }\end{array}$ & PDT/PTT & Liquid-phase exfoliation & HeLa cells & $\begin{array}{l}\text { The complex showed good PDT / PTT activity. } \\
\text { The in vivo fluorescence imaging displayed that } \\
\text { the complex accumulated in tumor cells and } \\
\text { synergetic antitumor efficacy was observed due } \\
\text { to incorporation of Ce } 6\end{array}$ & [137] \\
\hline BPNS-bPEI-PEG & PTT/Immunotherapy & Liquid-phase exfoliation & HepG2, RAW264.7 and 4T1 cell lines & $\begin{array}{l}\text { The BPNS grafted CpG (immunologic adjuvant) } \\
\text { provided as an efficient necroptosis modulator } \\
\text { to mediate PTT and anticancer immunotherapy } \\
\text { by activating the immunogenic cell death and } \\
\text { initiating the immune response. }\end{array}$ & [138] \\
\hline $\begin{array}{c}\text { NE-BP } \\
\text { Neutrophil-coated BP } \\
\text { nanoflakes adsorbed on PEI } \\
\text { and TGF- } \beta \text { inhibitor }\end{array}$ & PDT/PTT/Immunotherapy & Liquid-phase exfoliation & 4T1 lung cancer cell line & $\begin{array}{l}\text { The complex showed enhanced stability, high } \\
\text { tumor accumulation, and superior PDT/PTT } \\
\text { efficiency in comparison with bare BP resulting } \\
\text { in suppressed tumors metastasis. }\end{array}$ & [139] \\
\hline
\end{tabular}




\subsubsection{Wound Healing}

The complicated wound healing process begins immediately after the injury and regains the integrity of the skin within 12 weeks. Inflammation, new tissue growth, tissue remodeling, and regeneration are the three phases in the wound healing process. [140,141]. An impairment in the wound healing process can cause serious complications and lead to disease. [142]. With the increase in side effects that mainly affect the liver, the use of conventional pharmaceutical drugs for a longer period has been a major concern in the medical field. [143]. As a result, the need for an accelerated wound healing process began with the use of natural polymers such as polysaccharides and proteins but lacked bioactivity and the potential to enhance the wound healing process. Thus, extensive research has been carried out on surface-architected nanomaterials integrated in the polymeric network to obtain nanomaterials that augment the wound healing process [144]. A study reports the use of BPNS exfoliated using silk fibroin (BP@SF) as a novel wound dressing for antibacterial and rapid wound healing via NIR-mediated photothermal therapy. The BPNSs were synthesized using liquid exfoliation using silk fibroin as the exfoliating agent. The cytotoxicity assay was tested using human synovial fibroblast cells while the antimicrobial activity was assessed using E. coli and B. subtilis as representative models. In vivo studies were carried out on Kunming mice by making a $5 \mathrm{~mm}^{2}$ wound and infecting it with an E. coli suspension. The SF molecules were found to be effectively bonded to BPNS by strong hydrophobic interactions with particle sizes of $200 \mathrm{~nm}$. The BP@SF were found to be stable for 14 days unlike the BPNS synthesized using N-methyl-2-pyrrolidone (NMP) which degraded within 7 days on exposure to air and water. In vitro PTT displayed good antimicrobial activity of BP@SF compared to BP@SF without irradiation, while in vivo results showed remarkable wound repair and regeneration with complete healed wound within 5 days [145]. Since oxygen is a prerequisite for quick wound healing, research findings have shown that several oxygen carriers can supply $\mathrm{O}_{2}$ to the surface wound that does not reach the internal layers of the wound and also find difficulty in controllable delivery of $\mathrm{O}_{2}$, thereby affecting its practical performance. Therefore, Zhang et al. prepared microneedles loaded with BPQD and $\mathrm{Hb}$ for the NIR-mediated controllable delivery of oxygen to the skin to promote wound healing as shown in Figure 8. BPQDs were loaded onto the microneedle tips which were constructed of GelMA and PVA as the backing layer. The in vitro studies were carried out using a standard fibroblast cell line while the in vivo studies were carried out on Type 1 diabetic rat infected with a $1 \mathrm{~cm}$ thick cutaneous wound. On application of the microneedle to the affected skin, the PVA backing layer dissolved within a few minutes, causing the GelMA tips to be entrapped in the wound. On exposure to NIR, the BPQDs increased the local temperature to $50{ }^{\circ} \mathrm{C}$ within $2 \mathrm{~min}$, causing the $\mathrm{Hb}$ to release oxygen in a controllable manner. The in vivo results showed complete wound recovery within 9 days, demonstrating the potential for BP in wound associated pathological events [97].

\subsubsection{Neurodegenerative Disease}

Neurodegenerative conditions are a group of uncurable heterogeneric disorders, leading to a gradual deterioration of nerve cells, affecting the central nervous system and the periphery nervous system. Tauopathies, amyloidosis, synucleinopathies, and Transactivation response DNA binding protein (43 TDP-43) proteinopathies are the most widely mentioned neurodegenerative disorders [146]. Studies have also reported that depressive symptoms are commonly observed in patients with cognitive disorders such as Alzheimer's and Parkinson's disease [147,148]. The treatment of such pathological brain circumstances is one of the most complicated aspects of modern medicine due to failure of maximum therapeutic compounds to effectively cross the BBB [149,150]. An ideal drug delivery carrier system would accumulate within the brain thereby crossing the BBB and releasing the drug to the specific targeted cells [151]. Recent studies have explored the potential of BP-based nanomaterials to improve the permeability of BBB to NIR exposure via PTT, since it can be used as an effective platform for drug molecules to be delivered 
intracerebrally. In a previous study, Paeoniflorin (Pae), an antiparkinsonian drug, was loaded within BPNS conjugated to Lactoferrin (brain targeting ligand) for systemic delivery (Lf@BP-Pae), as shown in Figure 9. Using liquid-phase exfoliation, BPNSs were synthesized and the complex had a particle size ranging between 70 and $250 \mathrm{~nm}$. The nanocomplex exhibited superior PTT efficacy with a temperature elevation of $41^{\circ} \mathrm{C}$ within $480 \mathrm{~s}$ of irradiation. The in vitro neuroprotective efficacy was tested on human neuroblastoma $\mathrm{SH}-$ SY5Y cells, which revealed no in vitro toxicity while the complex was primarily localized in the mitochondria. In in vitro and in vivo experimentations, the increased BBB permeation of the nanocomplex and drug release on NIR irradiation at $808 \mathrm{~nm}$ was clearly evident. The mechanism of BBB permeation was found to be endocytosis followed by transcytosis. Additionally, the complex prevented neuronal damage, thereby portraying an antioxidant mechanism. These findings demonstrate that the fabricated complex can be utilized for systemic delivery of antiparkinsonian drugs or drugs for the therapy of other neurological diseases [152].

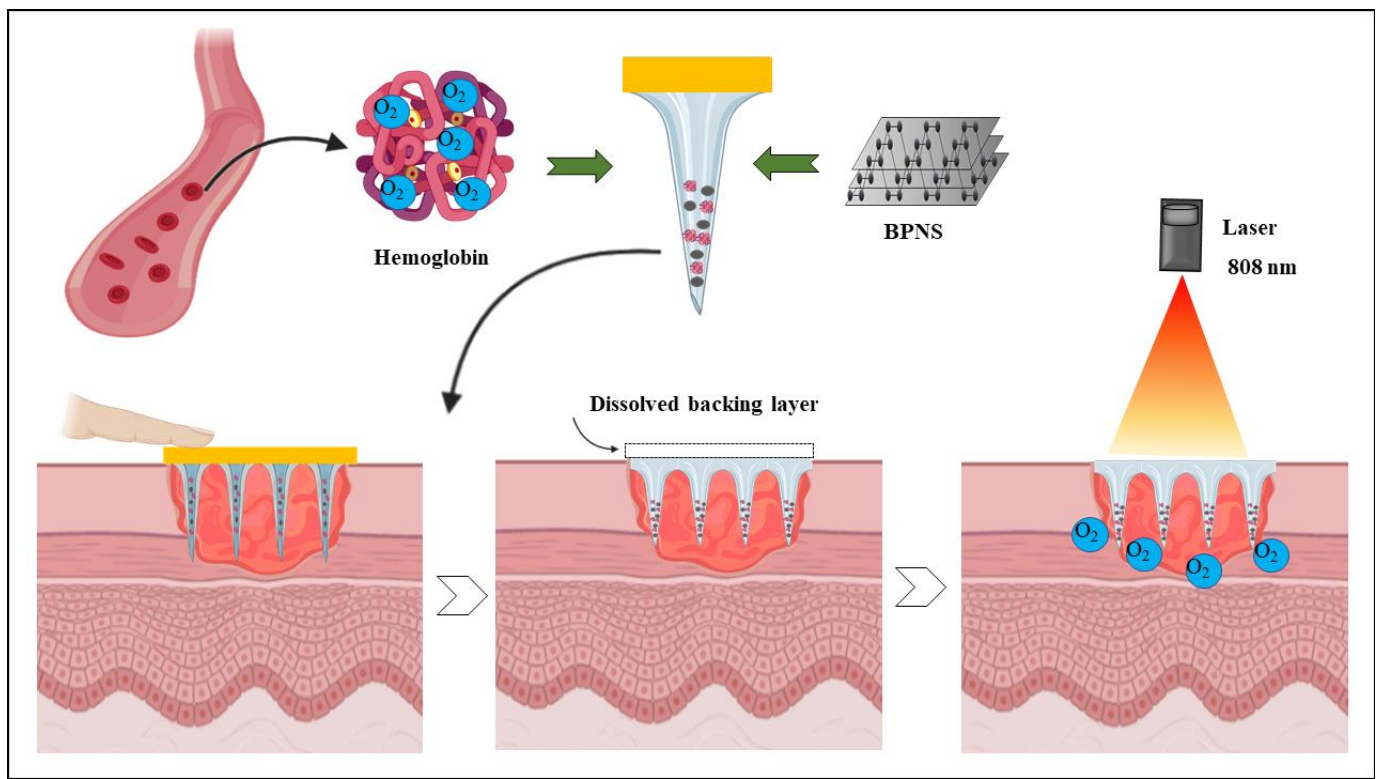

Figure 8. Schematic representation enumerating Near infrared region (NIR)-mediated controlled release of $\mathrm{O}_{2}$ for wound healing using microneedles encapsulating BPNS and $\mathrm{Hb}$.

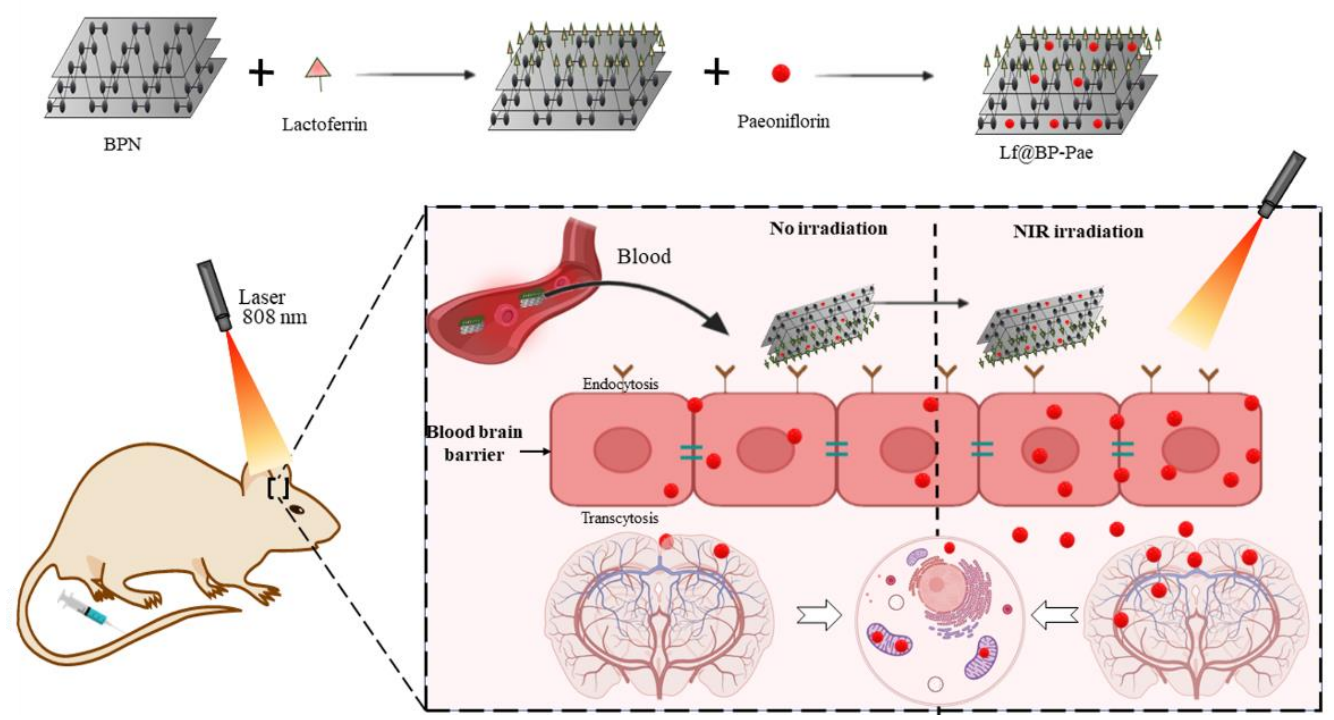

Figure 9. Schematic representation of Lf@BP-Pae synthesis and its therapeutic application in treatment of Parkinson disease. 
Jin and colleagues developed a BPNS-based drug delivery platform for synergistic PTT/chemotherapy of depression using fluoxetine as the antidepressant drug. The BPNSs were synthesized using a liquid exfoliation technique. The BPNS had a particle size of $200 \mathrm{~nm}$ proved by SEM and TEM analysis. It was observed that, under $808 \mathrm{~nm}$ NIR irradiation, the temperature of the BPNS solution raised with dose and approx. $90 \%$ of the drug was released within 30 min of irradiation. The BPNSs were highly biocompatible and showed no toxicity towards HUVEC, LLC, 4T1, and U251 cells. The in vivo results showed that BPNS loaded with the drug shortened the therapy duration compared to the conventional fluoxetine treatment [153]. Recent studies have shown that increased levels of biometals (transition-metal dyshomeostasis), especially copper, have led to the onset and progression of neurodegenerative diseases [154]. In a recent study, BPs were utilized as $\mathrm{Cu}^{2+}$ scavengers for neurogenerative disorder therapy. BPNS enhanced BBB permeability via PTT irradiation, therefore increasing the drug efficacy. In the physiological state, BPNS was found to serve as an antioxidant to minimize the accumulation of $\mathrm{Cu}^{2+}$ dyshomeostasis-related cytotoxic ROS. BPNS also possesses high stability and excellent biocompatibility, bestowing its biosafety in neurodegenerative disorders [7].

\section{2. $B P$ and $3 D$ Printing}

The 3D printing industry, considered as a technological revolution, offers great opportunities in a variety of arenas including tissue engineering. Various biomaterials, including artificial scaffolding, have been widely built up for bone regeneration by applying advanced techniques for design and production [155]. Nevertheless, studies related to the application and design of 3D printing technology for targeted therapies of cancer are still in infancy. So far, there are hand countable research papers available addressing the nano biointeractions of phosphorene with body fluids as a specific biotrigger for osseointegration and osteogenesis. The concept behind such an interaction is to transform the degraded $\mathrm{BP}$ nanosheets into P-agents (in situ) capable of improving bone regeneration. In this context, a novel therapeutic system was designed to formulate a bifunctional BP-Bioglass (BG) scaffold by integrating the BP nanosheets in a 3D-printed BG, for the phototherapy of osteosarcoma followed by bone regeneration. First, following the implantation of a BP-BG scaffold into the bone defects resulting from surgical resection, the photothermal treatment was implemented out on the basis of the exceptional photothermal efficiency of BP nanosheets. Subsequently, BG 3D-printed scaffolds exhibit their vital roles in the successful accomplishment of cell proliferation, vascularization, angiogenesis [155,156], and differentiation, owing to their intrinsic properties for osteoconduction, osteoinduction, and osteogenesis [157]. Eventually, the scaffolds slowly degrade as new bone tissue materials, followed by the reconstruction of pathologically changed areas. The bifunctional BG scaffold supports both BP nanosheets and tumor-induced flaws in the bone. The inherent physicochemical characteristics of BP nanosheets offer an exceptional in situ biomineralization ability to aid the process of osseointegration, and the phosphate ions released in the process of degradation of BP act as anionic ligands to interact with calcium ions and promote the formation of calcium phosphate nanoparticles that assist in bone regeneration and increase biomineralization [158]. Similar studies were performed in another studies, wherein 3D-printed BPNS-BG scaffolds were developed for the photothermal therapy of osteosarcoma and bone regeneration. On NIR irradiation, the BP scaffold caused degradation to phosphate via PTT and bound the surrounding calcium to achieve biological mineralization. The in vitro and in vivo results proved that a BP scaffold has high osteogenic potential and plays critical roles in cell proliferation, differentiation and vascularization, thus it can be used for dual purposes-i.e., to treat osteosarcoma and act as a matrix to support BPNS [158].

The synergistic effect of BP and graphene oxide nanosheets on cell osteogenesis was assessed in a previous study. BP was initially wrapped in the nanosheets of negatively charged GO and then adsorbed together onto three-dimensional scaffolds of poly(propylene fumarate). GO nanosheets offer an increased surface area that would 
help in enhancing the cell attachment. Moreover, a continuous release of phosphate resulting from slow oxidation of the BP nanosheets packed in GO layers functions as a major facilitator of osteoblast differentiation to trigger cell osteogenesis towards a new bone formation. Results of various studies performed in the study proved that synergistic combination stimulated the osteogenesis and cell proliferation, rendering the method a promising strategy for tissue engineering applications [159]. In another research, a multifunctional scaffold was developed based on the strategy of "first kill and then regenerate". To achieve sequential elimination of the tumors with the suppression of recurrence and enhanced tissue regeneration, the $\mathrm{w} / \mathrm{o}$ polyester emulsion inks incorporated with various functional agents, was developed. The tumor resection-induced defects in the tissue were addressed by using BP nanosheets (photothermal agent), doxorubicin (anticancer agent), beta-tricalcium phosphate (proliferation and maturation of the mesenchymal stem cells derived from the bone marrow), and osteogenic peptide (osteogenic factor). The developed scaffolds had a porous biomimetic assembly, photothermal effect, and adequate mechanical strength, and showed a controlled release of peptide and DOX. The use of such a multifunctional scaffold in the tumor-bearing nude mice resulted in the elimination of tumors and prevented its recurrence. Furthermore, the osteogenic differentiation of mesenchymal stem cells derived from rat was achieved, owing to the synergistic effects of sustained peptide release and the bony environment, and BP nanosheets were found to reduce the long-term toxicity associated with the release of DOX during bone regeneration [160].

\subsection{Bioimaging}

Photoacoustic (PA) imaging provides superior contrast images and sensitivity, highdimensional resolution, and 3D imaging which are depth-resolved. Thus, it functions as one of the emerging noninvasive cancer imaging techniques. Consequently, it has been demonstrated to be exceptional in many other conventional optical imaging techniques that help imaging-guided therapy [161]. PA is capable of generating optical contrast images with high-dimensional resolutions in tissue areas with a depth of 5-6 cm and manages background-less tumor recognition [162]. Since the PA signal initiates from the tumor location, the signal amplitude, especially at the initial stage of cancer, is considerably low. Therefore, efficient exogenous contrast agents have been researched for in vivo PA tumor imaging, such as NIR absorbing nanomaterials [163,164]. Because of its remarkable electronic and optical characteristics, BP have been recognized as an effective substance for bioimaging. The tunable band range for this substance varies between 0.3 and $2.0 \mathrm{eV}$, representing the values from bulk to a monolayer, respectively [165]. A multilayer BP may therefore enable photodetection over a large insubstantial area [166]. As outlined above, BP is very responsive to oxygen and water surface alterations can be carried out to upgrade its stability. One study, for instance, demonstrates the surface alignment of a sulfonic ester form of titanium ligand (TiL4) along with BPQDs to boost its stability for utilization as PA agent for cancer bioimaging [167]. TiL4-synchronized BPQDs demonstrated greater stability in a water dispersion relative to the plain BPQDs. Because of their strong NIR extinction coefficient, they even demonstrated better PA efficiency than AuNPs. In particular, $\mathrm{BPQDs}$ can accumulate gradually at a large concentration in the tumor through increased permeability and retention (EPR) effects. The high spatial resolution and exceptional sensitivity towards tumor detection illustrate their potential utilization as contrast agents for PA imaging in MCF-7 tumor cells and their applicability as photodetectors for hyperspectral imaging in biomedical studies $[167,168]$. The utilization of polyethylene glycol-(PEG)ylated BPNP for both PA imaging and cancer treatment applications was previously recorded in a study [166]. The surface coating of PEG and the fractional oxidation of BPNPs allow exceptional water solubility and stability. In vivo study displayed that after $24 \mathrm{~h}$ postintravenous injection of PEGylated BPNP, the tumor reserved a higher signal intensity in comparison with kidney and liver. Consequently, by the impact of enhanced permeability and retention, the nanomaterials have a long retention span in the tumor, whereas they 
can also be gradually extracted from the kidney and liver. Such characteristics make them vastly appropriate for cancer PA imaging.

\section{Biodegradation and Toxicity of BP}

BP has been extensively used in field-effect transistors and solar cells, and this has ignited a surging wave of interest in the exploration of BP in biomedicine especially as imaging agents, photothermal agents, cancer theranostic agents, drug carriers, and in bone regeneration [78]. However, in the physiological environment, the biological effects of BP-related nanomaterials are not well established, leading to toxicity and biosafety concerns, which limits their clinical applications $[169,170]$. Previous research claims that the potential toxicity of BP nanomaterials in biological systems to be size- [171] and layerdependent [171-173]. In this context, the biocompatibility of BPQDs was assessed in a study in which the authors used HeLa cells to conduct BP nanodot cytotoxicity at concentrations ranging from $0-3 \mathrm{mg} / \mathrm{mL}$ via MTT assay. The findings revealed that the BP nanodots exhibited little or no in vitro cytotoxicity at $1.0 \mathrm{mg} / \mathrm{mL}$; however, at $3.0 \mathrm{mg} / \mathrm{mL}$, cell necrosis was observed due to the crystallinity of BP dots, implicating good biocompatibility of BP nanodots at lower concentrations [174]. In contrast to graphene, few research trials have demonstrated the lower toxic potential of BP as it quickly degrades to phosphorous ions in the presence of water and oxygen, which also acts as an added aid in the case of bone regeneration [175]. Another study revealed the cytotoxicity of PEG-modified BPQDs to different types of cells such as 293T, MCF-7, and C6 (glioma) cells. The findings revealed that the BPQDs did not exhibit cytotoxicity even at a concentration of 200 ppm on either of the cell lines, indicating the suitability of BP for biomedical use [45]. To address the challenges associated with toxicity, the surface functionalization of BP has proven to cause lower toxicity compared to bare BP. The toxicity mechanism of BP at a cellular level is still unknown, even though the in vivo biological effects of BP are well reported. For instance, a study explored the in vitro and in vivo toxicity of BPNS and the results of the in vitro study on a human bronchial epithelial cell line showed that BPNS interferes with membrane potential, leading to elevated ROS generation which activates caspase- 3 leading to cell apoptosis. The in vivo study showed that a single intravenous injection of BPNS does not cause organ damage in mice; however, multiple injections of BPNS led to adverse effects on the mice liver and renal functions [176]. Expertise on development of in vivo animal models will therefore ease in establishing the biocompatibility of BP-related nanomaterials, which in turn will help to speed up the clinical approval.

\section{Future Prospective}

$\mathrm{BP}$, as a vital addition of the family of $2 \mathrm{D}$ nanomaterials, has the capability to perform well beyond the (opto) electronics in a range of applications. To improve the stability of BP, the surface outer coating and surface alteration by chemicals and doping have successfully been achieved. Their applications must also be unveiled in the near future in the area of nanoparticles conjugated for targeted gene therapy using aptamers other than miRNA or siRNA, as these area of research have been less explored and have great potential in terms of biomedical applications [151,152]. In the area of advancing medicine, $\mathrm{BP}$-based nanomaterials were also being examined. To date, the cell response to the BP substrate has not yet been reported in terms of the functional properties of cells. The effect of BP film on cell viability, cell differentiation and proliferation would therefore be interesting to study to give a clear interpretation of BP cellular interconnection for regenerative medical applications. Since BP has high electrical properties in comparison with other 2D materials, BP can effectively explore and enhance the electrical conductivity of neurons or cardiomyocytes, by integrating them with BP to enable cardiomyocyte or neural regeneration. In extracellular rigidity, artificial scaffolds such as hydrogels of gelatin methacryloyl (GelMA) with tunable strengths play a significant part in conveying exact mechanical indications to the adherent cells $[177,178]$. In comparison to those grown on the GelMA polymer, cardiomyocytes inscribed on carbon nanotubes, hybrid hydrogels 
of graphene and GO-polymers, significantly enhanced morphogenesis of cardiac tissue, caused stronger beating behavior and a greater voluntary beating rate $[179,180]$. The prospective use of a hybrid hydrogel BP-GelMA scaffold for neural or cardiac tissue regeneration is, therefore, promising [169].

Molecular dynamics (MDs) simulations is one of the specific techniques currently existing to model the weak dispersive hydrogen bonding and polar interactions that control liquid-phase exfoliation (LPE)-based length and time scales of solvent-nanomaterial interfaces, combining unprecedented speed and accuracy with electronic structure simulations of continuum approaches [181]. Quantum density functional theory (DFT) is unable to describe the interaction of electrons well enough to reliably describe the weak van der Waals force to a maximum of a few $\mathrm{kJ} \cdot \mathrm{mol}^{-1}$. Dispersion modifications can be used to boost this limitation, but somehow the degree of empiricism also correlated with van der Waals forces and remains equivalent to the classical force fields [182,183]. Furthermore, the time scales and size which can be expressed with DFT are much less in the current scenario. Following a theory of colloidal aggregation, Shih et al., in their study, utilized MD simulations to predict the colloidal stability of graphene based on its molecular structure [184]. Kamath and Baker used a particular kind of in silico technique to inspect the efficacy of ionic graphene liquids [185-187]. Graphene MD simulation studies reveal various key facts, and similar studies are also required to explore different aspects of BP. All these findings have demonstrated the impact of molecular confinement mostly on kinetics and energetics of aggregation and exfoliation, which highlights the need to consider the solubility energetics in addition to the consequence of solvent-phase microscopic structures. Studies of MD simulations provide insight into different topics, which are important for future development. Other 2D materials other than quantum dots recently showed excellent photothermal conversion efficiencies in cancer therapy. Such 2D materials are found to promote excellent physicochemical properties for different applications, taking into account the resemblances in the function and morphological features between BP and other layered 2D materials of Group III (borophene), Group IV (stanene, germanene and silicene), and Group VA (such as arsene, bismuthene and antimonene) [188]. BP for gas sensing has been demonstrated in various studies as a highly precise material, but its implementation in medical diagnosis is still not investigated thoroughly yet. Hence, upcoming research may also include BP as breath gas analyzer to measure of the levels of nitric oxide and ammonia present in the breath, which allows to detect different diseases such as asthma and renal disease [189]. It would also be fascinating to explore the impact of BP combined with 2D materials in order to construct a combination therapeutic system for cancer therapy. We assume that there would be more research that focuses on use of BP from a biomedical perspective in the near future, with several other remaining challenges and opportunities.

\section{Conclusions}

This present paper provides a summary of BP research for biomedical implementation in the future, including drug delivery, phototherapy, 3D printing, theranostics, bioimaging, and cancer therapy. Layered BP is recognized as a potential candidate to overtake graphene as an innovative and favorable substance for the future nanomedicine and photonics such as photovoltaic cells, photodetectors, and other logical devices, due to its elevated mobility by the carriers, excellent current saturation, controllable bandgap and angular-dependent characteristics. Therefore, in this area, more intense and effective research must be carried out [169]. To date, studies on the implementation of BPs have focused primarily on nanodevices, semiconductors, optoelectronics, and other electronics, whereas significantly fewer attempts have been undertaken to extend its implementation to the other fields, such as biological applications. Regardless of the important progress, studies in this area are still at the budding stage when compared to other well explored 2D material studies. It remains a challenge, from a basic approach, to produce good-quality and bulk BP samples. Hence, for prospective biomedical materials with less toxicity, it is essential to have a tough and 
efficient method for high value BP bulk production with specific control over its variables, including number of layers, concentration, size, and surface alterations [13].

Funding: This research received no external funding.

Acknowledgments: The authors are thankful to Manipal Academy of Higher Education (MAHE), Manipal, India (for Postdoctoral Fellowship to Abhijeet Pandey and TMA Pai Doctoral Fellowship to Ajinkya Nikam, Gasper Fernandes, Sanjay Kulkarni and Subham Das) and the All India Council for Technical Education (AICTE), Government of India, New Delhi (for National Doctoral Fellowship to Bharath S Padya). The authors are also thankful to Manipal and Manipal College of Pharmaceutical Sciences, MAHE, Manipal, India for providing the necessary facilities. The authors also acknowledge BioRender for providing online platform to create the images.

Conflicts of Interest: The authors declare no conflict of interest.

\section{References}

1. Bridgman, P.W. Two New Modifications of Phosphorus. J. Am. Chem. Soc. 1914, 36, 1344-1363. [CrossRef]

2. Hultgren, R.; Gingrich, N.S.; Warren, B.E. The Atomic Distribution in Red and Black Phosphorus and the Crystal Structure of Black Phosphorus. J. Chem. Phys. 1935, 3, 351-355. [CrossRef]

3. Nikam, A.N.; More, M.P.; Pandey, A.P.; Patil, P.O.; Patil, A.G.; Deshmukh, P.K. Design and Development of Thiolated Graphene Oxide Nanosheets for Brain Tumor Targeting. Int. J. Polym. Mater. Polym. Biomater. 2020, 69, 611-621. [CrossRef]

4. Qiu, M.; Ren, W.X.; Jeong, T.; Won, M.; Park, G.Y.; Sang, D.K.; Liu, L.-P.; Zhang, H.; Kim, J.S. Omnipotent Phosphorene: A next-Generation, Two-Dimensional Nanoplatform for Multidisciplinary Biomedical Applications. Chem. Soc. Rev. 2018, 47, 5588-5601. [CrossRef] [PubMed]

5. Hanlon, D.; Backes, C.; Doherty, E.; Cucinotta, C.S.; Berner, N.C.; Boland, C.; Lee, K.; Harvey, A.; Lynch, P.; Gholamvand, Z. Liquid Exfoliation of Solvent-Stabilized Few-Layer Black Phosphorus for Applications beyond Electronics. Nat. Commun. 2015, 6, 1-11. [CrossRef]

6. Li, L.; Yu, Y.; Ye, G.J.; Ge, Q.; Ou, X.; Wu, H.; Feng, D.; Chen, X.H.; Zhang, Y. Black Phosphorus Field-Effect Transistors. Nat. Nanotechnol. 2014, 9, 372. [CrossRef]

7. Chen, W.; Ouyang, J.; Yi, X.; Xu, Y.; Niu, C.; Zhang, W.; Wang, L.; Sheng, J.; Deng, L.; Liu, Y.; et al. Black Phosphorus Nanosheets as a Neuroprotective Nanomedicine for Neurodegenerative Disorder Therapy. Adv. Mater. 2018, 30, 1703458. [CrossRef]

8. Lin, S.; Li, Y.; Lu, W.; Chui, Y.S.; Rogée, L.; Bao, Q.; Lau, S.P. In Situ Observation of the Thermal Stability of Black Phosphorus. 2D Mater. 2017, 4. [CrossRef]

9. Maruyama, Y.; Suzuki, S.; Kobayashi, K.; Tanuma, S. Synthesis and Some Properties of Black Phosphorus Single Crystals. Phys. BC 1981, 105, 99-102. [CrossRef]

10. Lee, T.H.; Kim, S.Y.; Jang, H.W. Black Phosphorus: Critical Review and Potential for Water Splitting Photocatalyst. Nanomaterials 2016, 6, 194. [CrossRef]

11. Lange, S.; Schmidt, P.; Nilges, T. Au3SnP7@Black Phosphorus: An Easy Access to Black Phosphorus. Inorg. Chem. 2007, 46, 4028-4035. [CrossRef] [PubMed]

12. Köpf, M.; Eckstein, N.; Pfister, D.; Grotz, C.; Krüger, I.; Greiwe, M.; Hansen, T.; Kohlmann, H.; Nilges, T. Access and in Situ Growth of Phosphorene-Precursor Black Phosphorus. J. Cryst. Growth 2014, 405, 6-10. [CrossRef]

13. Anju, S.; Ashtami, J.; Mohanan, P.V. Black Phosphorus, a Prospective Graphene Substitute for Biomedical Applications. Mater. Sci. Eng. C 2019, 97, 978-993. [CrossRef] [PubMed]

14. Inamuddin; Boddula, R.; Asiri, A.M. (Eds.) Black Phosphorus: Synthesis, Properties and Applications; Engineering Materials; Springer International Publishing: Berlin/Heidelberg, Germany, 2020; ISBN 978-3-030-29554-7.

15. Woomer, A.H.; Farnsworth, T.W.; Hu, J.; Wells, R.A.; Donley, C.L.; Warren, S.C. Phosphorene: Synthesis, Scale-up, and Quantitative Optical Spectroscopy. ACS Nano 2015, 9, 8869-8884. [CrossRef] [PubMed]

16. Nicolosi, V.; Chhowalla, M.; Kanatzidis, M.G.; Strano, M.S.; Coleman, J.N. Liquid Exfoliation of Layered Materials. Science 2013, 340. [CrossRef]

17. Coleman, J.N.; Lotya, M.; O’Neill, A.; Bergin, S.D.; King, P.J.; Khan, U.; Young, K.; Gaucher, A.; De, S.; Smith, R.J. Two-Dimensional Nanosheets Produced by Liquid Exfoliation of Layered Materials. Science 2011, 331, 568-571. [CrossRef] [PubMed]

18. Bourlinos, A.B.; Georgakilas, V.; Zboril, R.; Steriotis, T.A.; Stubos, A.K.; Trapalis, C. Aqueous-Phase Exfoliation of Graphite in the Presence of Polyvinylpyrrolidone for the Production of Water-Soluble Graphenes. Solid State Commun. 2009, 149, $2172-2176$. [CrossRef]

19. Vadukumpully, S.; Paul, J.; Valiyaveettil, S. Cationic Surfactant Mediated Exfoliation of Graphite into Graphene Flakes. Carbon 2009, 47, 3288-3294. [CrossRef]

20. Hughes, J.M.; Aherne, D.; Coleman, J.N. Generalizing Solubility Parameter Theory to Apply to One-and Two-dimensional Solutes and to Incorporate Dipolar Interactions. J. Appl. Polym. Sci. 2013, 127, 4483-4491. [CrossRef]

21. Coleman, J.N. Liquid Exfoliation of Defect-Free Graphene. Acc. Chem. Res. 2013, 46, 14-22. [CrossRef] 
22. Lin, S.; Chui, Y.; Li, Y.; Lau, S.P. Liquid-Phase Exfoliation of Black Phosphorus and Its Applications. FlatChem 2017, 2, 15-37. [CrossRef]

23. Achee, T.C.; Sun, W.; Hope, J.T.; Quitzau, S.G.; Sweeney, C.B.; Shah, S.A.; Habib, T.; Green, M.J. High-Yield Scalable Graphene Nanosheet Production from Compressed Graphite Using Electrochemical Exfoliation. Sci. Rep. 2018, 8, 1-8. [CrossRef] [PubMed]

24. Yi, M.; Shen, Z. A Review on Mechanical Exfoliation for the Scalable Production of Graphene. J. Mater. Chem. A 2015, 3 , 11700-11715. [CrossRef]

25. Lu, W.; Nan, H.; Hong, J.; Chen, Y.; Zhu, C.; Liang, Z.; Ma, X.; Ni, Z.; Jin, C.; Zhang, Z. Plasma-Assisted Fabrication of Monolayer Phosphorene and Its Raman Characterization. Nano Res. 2014, 7, 853-859. [CrossRef]

26. Bhoria, R.S. Enhancing Liquid Phase Exfoliation of Graphene in Organic Solvents with Additives. In Graphene and Its DerivativesSynthesis and Applications; IntechOpen: London, UK, 2019.

27. Xia, F.; Wang, H.; Jia, Y. Rediscovering Black Phosphorus as an Anisotropic Layered Material for Optoelectronics and Electronics. Nat. Commun. 2014, 5, 1-6. [CrossRef]

28. Mao, N.; Tang, J.; Xie, L.; Wu, J.; Han, B.; Lin, J.; Deng, S.; Ji, W.; Xu, H.; Liu, K. Optical Anisotropy of Black Phosphorus in the Visible Regime. J. Am. Chem. Soc. 2016, 138, 300-305. [CrossRef]

29. Lan, S.; Rodrigues, S.; Kang, L.; Cai, W. Visualizing Optical Phase Anisotropy in Black Phosphorus. Acs Photonics 2016, 3, 1176-1181. [CrossRef]

30. Tran, V.; Soklaski, R.; Liang, Y.; Yang, L. Tunable Band Gap and Anisotropic Optical Response in Few-Layer Black Phosphorus. arXiv 2014, arXiv:1402.4192.

31. Çakır, D.; Sahin, H.; Peeters, F.M. Tuning of the Electronic and Optical Properties of Single-Layer Black Phosphorus by Strain. Phys. Rev. B 2014, 90, 205421. [CrossRef]

32. Tran, V.; Soklaski, R.; Liang, Y.; Yang, L. Layer-Controlled Band Gap and Anisotropic Excitons in Few-Layer Black Phosphorus. Phys. Rev. B 2014, 89, 235319. [CrossRef]

33. Zhang, S.; Yang, J.; Xu, R.; Wang, F.; Li, W.; Ghufran, M.; Zhang, Y.-W.; Yu, Z.; Zhang, G.; Qin, Q. Extraordinary Photoluminescence and Strong Temperature/Angle-Dependent Raman Responses in Few-Layer Phosphorene. ACS Nano 2014, 8, 9590-9596. [CrossRef] [PubMed]

34. Liu, H.; Neal, A.T.; Zhu, Z.; Luo, Z.; Xu, X.; Tománek, D.; Ye, P.D. Phosphorene: An Unexplored 2D Semiconductor with a High Hole Mobility. ACS Nano 2014, 8, 4033-4041. [CrossRef] [PubMed]

35. Xu, Y.; Yan, B.; Zhang, H.-J.; Wang, J.; Xu, G.; Tang, P.; Duan, W.; Zhang, S.-C. Large-Gap Quantum Spin Hall Insulators in Tin Films. Phys. Rev. Lett. 2013, 111, 136804. [CrossRef] [PubMed]

36. Ospina, D.A.; Duque, C.A.; Correa, J.D.; Morell, E.S. Twisted Bilayer Blue Phosphorene: A Direct Band Gap Semiconductor. Superlattices Microstruct. 2016, 97, 562-568. [CrossRef]

37. Zhu, Z.; Tománek, D. Semiconducting Layered Blue Phosphorus: A Computational Study. Phys. Rev. Lett. 2014, 112, 176802. [CrossRef]

38. Guan, J.; Zhu, Z.; Tománek, D. Tiling Phosphorene. ACS Nano 2014, 8, 12763-12768. [CrossRef]

39. Boulfelfel, S.E.; Seifert, G.; Grin, Y.; Leoni, S. Squeezing Lone Pairs: The A 17 to A 7 Pressure-Induced Phase Transition in Black Phosphorus. Phys. Rev. B 2012, 85, 014110. [CrossRef]

40. Guan, J.; Zhu, Z.; Tománek, D. Phase Coexistence and Metal-Insulator Transition in Few-Layer Phosphorene: A Computational Study. Phys. Rev. Lett. 2014, 113, 046804. [CrossRef]

41. Khandelwal, A.; Mani, K.; Karigerasi, M.H.; Lahiri, I. Phosphorene-The Two-Dimensional Black Phosphorous: Properties, Synthesis and Applications. Mater. Sci. Eng. B 2017, 221, 17-34. [CrossRef]

42. Wang, H.; Hu, K.; Li, Z.; Wang, C.; Yu, M.; Li, Z.; Li, Z. Black Phosphorus Nanosheets Passivation Using a Tripeptide. Small 2018, 14, 1801701. [CrossRef]

43. Huang, W.-Q.; Wang, F.; Nie, X.; Zhang, Z.; Chen, G.; Xia, L.; Wang, L.-H.; Ding, S.-G.; Hao, Z.-Y.; Zhang, W.-J.; et al. Stable Black Phosphorus Nanosheets Exhibiting High Tumor-Accumulating and Mitochondria-Targeting for Efficient Photothermal Therapy via Double Functionalization. ACS Appl. Bio Mater. 2020, 3, 1176-1186. [CrossRef]

44. Zhang, J.; Ma, Y.; Hu, K.; Feng, Y.; Chen, S.; Yang, X.; Fong-Chuen Loo, J.; Zhang, H.; Yin, F.; Li, Z. Surface Coordination of Black Phosphorus with Modified Cisplatin. Bioconjug. Chem. 2019, 30, 1658-1664. [CrossRef] [PubMed]

45. Sun, Z.; Xie, H.; Tang, S.; Yu, X.-F.; Guo, Z.; Shao, J.; Zhang, H.; Huang, H.; Wang, H.; Chu, P.K. Ultrasmall Black Phosphorus Quantum Dots: Synthesis and Use as Photothermal Agents. Angew. Chem. Int. Ed. 2015, 54, 11526-11530. [CrossRef] [PubMed]

46. Wang, J.; Liang, D.; Qu, Z.; Kislyakov, I.M.; Kiselev, V.M.; Liu, J. PEGylated-Folic Acid-Modified Black Phosphorus Quantum Dots as near-Infrared Agents for Dual-Modality Imaging-Guided Selective Cancer Cell Destruction. Nanophotonics 2020, 9, $2425-2435$. [CrossRef]

47. Gao, N.; Nie, J.; Wang, H.; Xing, C.; Mei, L.; Xiong, W.; Zeng, X.; Peng, Z. A Versatile Platform Based on Black Phosphorus Nanosheets with Enhanced Stability for Cancer Synergistic Therapy. J. Biomed. Nanotechnol. 2018, 14, 1883-1897. [CrossRef]

48. Kumar, V.; Brent, J.R.; Shorie, M.; Kaur, H.; Chadha, G.; Thomas, A.G.; Lewis, E.A.; Rooney, A.P.; Nguyen, L.; Zhong, X.L.; et al. Nanostructured Aptamer-Functionalized Black Phosphorus Sensing Platform for Label-Free Detection of Myoglobin, a Cardiovascular Disease Biomarker. ACS Appl. Mater. Interfaces 2016, 8, 22860-22868. [CrossRef]

49. Xu, Y.; Ren, F.; Liu, H.; Zhang, H.; Han, Y.; Liu, Z.; Wang, W.; Sun, Q.; Zhao, C.; Li, Z. Cholesterol-Modified Black Phosphorus Nanospheres for the First NIR-II Fluorescence Bioimaging. ACS Appl. Mater. Interfaces 2019, 11, 21399-21407. [CrossRef] 
50. Lukyanov, A.N.; Torchilin, V.P. Micelles from Lipid Derivatives of Water-Soluble Polymers as Delivery Systems for Poorly Soluble Drugs. Adv. Drug Deliv. Rev. 2004, 56, 1273-1289. [CrossRef]

51. Professor, S.F.C.D. Polymeric Stabilization of Colloidal Dispersions. Donald H. Napper. Academic Press, New York, 1984. Pp. Xvi \& plus; 428. \$65.00. J. Dispers. Sci. Technol. 1985, 6, 497. [CrossRef]

52. Sun, C.; Xu, Y.; Deng, L.; Zhang, H.; Sun, Q.; Zhao, C.; Li, Z. Blood Circulation, Biodistribution, and Pharmacokinetics of Dextran-Modified Black Phosphorus Nanoparticles. ACS Appl. Bio Mater. 2018, 1, 673-682. [CrossRef]

53. Wu, F.; Zhang, M.; Chu, X.; Zhang, Q.; Su, Y.; Sun, B.; Lu, T.; Zhou, N.; Zhang, J.; Wang, J.; et al. Black Phosphorus NanosheetsBased Nanocarriers for Enhancing Chemotherapy Drug Sensitiveness via Depleting Mutant P53 and Resistant Cancer Multimodal Therapy. Chem. Eng. J. 2019, 370, 387-399. [CrossRef]

54. PRP-Chitosan Thermoresponsive Hydrogel Combined with Black Phosphorus Nanosheets as Injectable Biomaterial for Biotherapy and Phototherapy Treatment of Rheumatoid Arthritis. Biomaterials 2020, 239, 119851. [CrossRef] [PubMed]

55. Liu, S.; Luo, J.; Jiang, X.; Li, X.; Yang, M. Gold Nanoparticle-Modified Black Phosphorus Nanosheets with Improved Stability for Detection of Circulating Tumor Cells. Microchim. Acta 2020, 187, 397. [CrossRef] [PubMed]

56. Wang, Y.; Hu, X.; Zhang, L.; Zhu, C.; Wang, J.; Li, Y.; Wang, Y.; Wang, C.; Zhang, Y.; Yuan, Q. Bioinspired Extracellular Vesicles Embedded with Black Phosphorus for Molecular Recognition-Guided Biomineralization. Nat. Commun. 2019, 10, 2829. [CrossRef]

57. Wang, D.; Ge, C.; Liang, W.; Yang, Q.; Liu, Q.; Ma, W.; Shi, L.; Wu, H.; Zhang, Y.; Wu, Z.; et al. In Vivo Enrichment and Elimination of Circulating Tumor Cells by Using a Black Phosphorus and Antibody Functionalized Intravenous Catheter. Adv. Sci. 2020, 7, 2000940. [CrossRef] [PubMed]

58. Eswaraiah, V.; Zeng, Q.; Long, Y.; Liu, Z. Black Phosphorus Nanosheets: Synthesis, Characterization and Applications. Small 2016, 12, 3480-3502. [CrossRef]

59. Surrente, A.; Mitioglu, A.A.; Galkowski, K.; Tabis, W.; Maude, D.K.; Plochocka, P. Excitons in Atomically Thin Black Phosphorus. Phys. Rev. B 2016, 93, 121405. [CrossRef]

60. Lin, S.; Li, Y.; Qian, J.; Lau, S.P. Emerging Opportunities for Black Phosphorus in Energy Applications. Mater. Today Energy 2019, 12, 1-25. [CrossRef]

61. Qiao, J.; Kong, X.; Hu, Z.-X.; Yang, F.; Ji, W. High-Mobility Transport Anisotropy and Linear Dichroism in Few-Layer Black Phosphorus. Nat. Commun. 2014, 5, 1-7. [CrossRef]

62. Castellanos-Gomez, A.; Vicarelli, L.; Prada, E.; Island, J.O.; Narasimha-Acharya, K.L.; Blanter, S.I.; Groenendijk, D.J.; Buscema, M.; Steele, G.A.; Alvarez, J.V. Isolation and Characterization of Few-Layer Black Phosphorus. 2D Mater. 2014, 1, 025001. [CrossRef]

63. Li, L.; Ye, G.J.; Tran, V.; Fei, R.; Chen, G.; Wang, H.; Wang, J.; Watanabe, K.; Taniguchi, T.; Yang, L. Quantum Oscillations in a Two-Dimensional Electron Gas in Black Phosphorus Thin Films. Nat. Nanotechnol. 2015, 10, 608-613. [CrossRef] [PubMed]

64. Xu, X.; Chen, J.; Li, B. Phonon Thermal Conduction in Novel 2D Materials. J. Phys. Condens. Matter 2016, 28, 483001. [CrossRef] [PubMed]

65. Akahama, Y.; Utsumi, W.; Endo, S.; Kikegawa, T.; Iwasaki, H.; Shimomura, O.; Yagi, T.; Akimoto, S. Melting Curve of Black Phosphorous. Phys. Lett. A 1987, 122, 129-131. [CrossRef]

66. Su, L.; Zhang, Y. Temperature Coefficients of Phonon Frequencies and Thermal Conductivity in Thin Black Phosphorus Layers. Appl. Phys. Lett. 2015, 107, 071905. [CrossRef]

67. Jeon, S.G.; Shin, H.; Jaung, Y.H.; Ahn, J.; Song, J.Y. Thickness-Dependent and Anisotropic Thermal Conductivity of Black Phosphorus Nanosheets. Nanoscale 2018, 10, 5985-5989. [CrossRef] [PubMed]

68. Henry, L.; Svitlyk, V.; Mezouar, M.; Sifré, D.; Garbarino, G.; Ceppatelli, M.; Serrano-Ruiz, M.; Peruzzini, M.; Datchi, F. Anisotropic Thermal Expansion of Black Phosphorus from Nanoscale Dynamics of Phosphorene Layers. Nanoscale 2020, 12, $4491-4497$. [CrossRef] [PubMed]

69. Judek, J.; Gertych, A.P.; Świniarski, M.; Łapińska, A.; Dużyńska, A.; Zdrojek, M. High Accuracy Determination of the Thermal Properties of Supported 2D Materials. Sci. Rep. 2015, 5, 12422. [CrossRef]

70. Luo, Z.; Maassen, J.; Deng, Y.; Du, Y.; Garrelts, R.P.; Lundstrom, M.S.; Peide, D.Y.; Xu, X. Anisotropic In-Plane Thermal Conductivity Observed in Few-Layer Black Phosphorus. Nat. Commun. 2015, 6, 1-8. [CrossRef]

71. Zhou, Y.; Zhang, M.; Guo, Z.; Miao, L.; Han, S.-T.; Wang, Z.; Zhang, X.; Zhang, H.; Peng, Z. Recent Advances in Black PhosphorusBased Photonics, Electronics, Sensors and Energy Devices. Mater. Horiz. 2017, 4, 997-1019. [CrossRef]

72. Chaves, A.; Low, T.; Avouris, P.; Çakır, D.; Peeters, F.M. Anisotropic Exciton Stark Shift in Black Phosphorus. Phys. Rev. B 2015, 91, 155311. [CrossRef]

73. Yuan, H.; Liu, X.; Afshinmanesh, F.; Li, W.; Xu, G.; Sun, J.; Lian, B.; Curto, A.G.; Ye, G.; Hikita, Y.; et al. Polarization-Sensitive Broadband Photodetector Using a Black Phosphorus Vertical p-n Junction. Nat. Nanotechnol. 2015, 10, 707-713. [CrossRef]

74. Liu, S.; Huo, N.; Gan, S.; Li, Y.; Wei, Z.; Huang, B.; Liu, J.; Li, J.; Chen, H. Thickness-Dependent Raman Spectra, Transport Properties and Infrared Photoresponse of Few-Layer Black Phosphorus. J. Mater. Chem. C 2015, 3, 10974-10980. [CrossRef]

75. Fei, R.; Yang, L. Lattice Vibrational Modes and Raman Scattering Spectra of Strained Phosphorene. Appl. Phys. Lett. 2014, 105, 083120. [CrossRef]

76. Wu, J.; Mao, N.; Xie, L.; Xu, H.; Zhang, J. Identifying the Crystalline Orientation of Black Phosphorus Using Angle-resolved Polarized Raman Spectroscopy. Angew. Chem. Int. Ed. 2015, 54, 2366-2369. [CrossRef]

77. Pawbake, A.S.; Erande, M.B.; Jadkar, S.R.; Late, D.J. Temperature Dependent Raman Spectroscopy of Electrochemically Exfoliated Few Layer Black Phosphorus Nanosheets. RSC Adv. 2016, 6, 76551-76555. [CrossRef] 
78. Guo, Z.; Zhang, H.; Lu, S.; Wang, Z.; Tang, S.; Shao, J.; Sun, Z.; Xie, H.; Wang, H.; Yu, X.-F.; et al. From Black Phosphorus to Phosphorene: Basic Solvent Exfoliation, Evolution of Raman Scattering, and Applications to Ultrafast Photonics. Adv. Funct. Mater. 2015, 25, 6996-7002. [CrossRef]

79. Mutalik, S.; Pandey, A.; Mutalik, S. Nanoarchitectronics: A Versatile Tool for Deciphering Nanoparticle Interaction with Cellular Proteins, Nucleic Acids and Phospholipids at Biological Interfaces. Int. J. Biol. Macromol. 2020. [CrossRef]

80. Raychaudhuri, R.; Pandey, A.; Hegde, A.; Abdul Fayaz, S.M.; Chellappan, D.K.; Dua, K.; Mutalik, S. Factors Affecting the Morphology of Some Organic and Inorganic Nanostructures for Drug Delivery: Characterization, Modifications and Toxicological Perspectives. Expert Opin. Drug Deliv. 2020. [CrossRef]

81. Chen, L.; Qian, M.; Jiang, H.; Zhou, Y.; Du, Y.; Yang, Y.; Huo, T.; Huang, R.; Wang, Y. Multifunctional Mesoporous Black Phosphorus-Based Nanosheet for Enhanced Tumor-Targeted Combined Therapy with Biodegradation-Mediated Metastasis Inhibition. Biomaterials 2020, 236, 119770. [CrossRef]

82. Raucci, M.G.; Fasolino, I.; Caporali, M.; Serrano-Ruiz, M.; Soriente, A.; Peruzzini, M.; Ambrosio, L. Exfoliated Black Phosphorus Promotes in Vitro Bone Regeneration and Suppresses Osteosarcoma Progression through Cancer-Related Inflammation Inhibition. ACS Appl. Mater. Interfaces 2019, 11, 9333-9342. [CrossRef]

83. Phakatkar, A.H.; Firlar, E.; Alzate, L.; Song, B.; Narayanan, S.; Rojaee, R.; Foroozan, T.; Deivanayagam, R.; Banner, D.J.; ShahbazianYassar, R. TEM Studies on Antibacterial Mechanisms of Black Phosphorous Nanosheets. Int. J. Nanomedicine 2020, $15,3071$. [CrossRef] [PubMed]

84. Böhmert, L.; Voß, L.; Stock, V.; Braeuning, A.; Lampen, A.; Sieg, H. Isolation Methods for Particle Protein Corona Complexes from Protein-Rich Matrices. Nanoscale Adv. 2020, 2, 563-582. [CrossRef]

85. Cedervall, T.; Lynch, I.; Lindman, S.; Berggård, T.; Thulin, E.; Nilsson, H.; Dawson, K.A.; Linse, S. Understanding the NanoparticleProtein Corona Using Methods to Quantify Exchange Rates and Affinities of Proteins for Nanoparticles. Proc. Natl. Acad. Sci. 2007, 104, 2050-2055. [CrossRef] [PubMed]

86. Allen, T.M.; Hansen, C.; Martin, F.; Redemann, C.; Yau-Young, A. Liposomes Containing Synthetic Lipid Derivatives of Poly (Ethylene Glycol) Show Prolonged Circulation Half-Lives in Vivo. Biochim. Biophys. Acta BBA-Biomembr. 1991, 1066, 29-36. [CrossRef]

87. Ânia, M.; Emilio, R.; Angel, M.; Rafael, G.; Manuel, F. Protein Interactions and Nanomaterials: A Key Role of the Protein Corona in Nanobiocompatibility. Protein-Protein Interact. Assays 2018, 29.

88. Mo, J.; Xu, Y.; Wang, X.; Wei, W.; Zhao, J. Exploiting the Protein Corona: Coating of Black Phosphorus Nanosheets Enables Macrophage Polarization via Calcium Influx. Nanoscale 2020, 12, 1742-1748. [CrossRef]

89. Mo, J.; Xie, Q.; Wei, W.; Zhao, J. Revealing the Immune Perturbation of Black Phosphorus Nanomaterials to Macrophages by Understanding the Protein Corona. Nat. Commun. 2018, 9, 1-11. [CrossRef]

90. Han, M.; Zhu, L.; Mo, J.; Wei, W.; Yuan, B.; Zhao, J.; Cao, C. Protein Corona and Immune Responses of Borophene: A Comparison of Nanosheet-Plasma Interface with Graphene and Phosphorene. ACS Appl. Bio Mater. 2020. [CrossRef]

91. Ray, S.J. First-Principles Study of MoS2, Phosphorene and Graphene Based Single Electron Transistor for Gas Sensing Applications. Sens. Actuators B Chem. 2016, 222, 492-498. [CrossRef]

92. Wang, H.; Yang, X.; Shao, W.; Chen, S.; Xie, J.; Zhang, X.; Wang, J.; Xie, Y. Ultrathin Black Phosphorus Nanosheets for Efficient Singlet Oxygen Generation. J. Am. Chem. Soc. 2015, 137, 11376-11382. [CrossRef]

93. Tayari, V.; Hemsworth, N.; Fakih, I.; Favron, A.; Gaufrès, E.; Gervais, G.; Martel, R.; Szkopek, T. Two-Dimensional Magnetotransport in a Black Phosphorus Naked Quantum Well. Nat. Commun. 2015, 6, 7702. [CrossRef] [PubMed]

94. Tao, W.; Zhu, X.; Yu, X.; Zeng, X.; Xiao, Q.; Zhang, X.; Ji, X.; Wang, X.; Shi, J.; Zhang, H.; et al. Black Phosphorus Nanosheets as a Robust Delivery Platform for Cancer Theranostics. Adv. Mater. Deerfield Beach Fla 2017, 29. [CrossRef] [PubMed]

95. Huang, K.; Wu, J.; Gu, Z. Black Phosphorus Hydrogel Scaffolds Enhance Bone Regeneration via a Sustained Supply of CalciumFree Phosphorus. ACS Appl. Mater. Interfaces 2019, 11, 2908-2916. [CrossRef] [PubMed]

96. Wang, S.; Weng, J.; Fu, X.; Lin, J.; Fan, W.; Lu, N.; Qu, J.; Chen, S.; Wang, T.; Huang, P. Black Phosphorus Nanosheets for Mild Hyperthermia-Enhanced Chemotherapy and Chemo-Photothermal Combination Therapy. Nanotheranostics 2017, 1, 208-216. [CrossRef]

97. Zhang, X.; Chen, G.; Liu, Y.; Sun, L.; Sun, L.; Zhao, Y. Black Phosphorus-Loaded Separable Microneedles as Responsive Oxygen Delivery Carriers for Wound Healing. ACS Nano 2020, 14, 5901-5908. [CrossRef]

98. Xie, H.; Shao, J.; Ma, Y.; Wang, J.; Huang, H.; Yang, N.; Wang, H.; Ruan, C.; Luo, Y.; Wang, Q.-Q.; et al. Biodegradable Near-Infrared-Photoresponsive Shape Memory Implants Based on Black Phosphorus Nanofillers. Biomaterials 2018, 164, 11-21. [CrossRef]

99. Bhattacharjee, P.; Naskar, D.; Maiti, T.K.; Bhattacharya, D.; Kundu, S.C. Investigating the Potential of Combined Growth Factors Delivery, from Non-Mulberry Silk Fibroin Grafted Poly( $\varepsilon$-Caprolactone)/Hydroxyapatite Nanofibrous Scaffold, in Bone Tissue Engineering. Appl. Mater. Today 2016, 5, 52-67. [CrossRef]

100. Tang, D.; Tare, R.S.; Yang, L.-Y.; Williams, D.F.; Ou, K.-L.; Oreffo, R.O.C. Biofabrication of Bone Tissue: Approaches, Challenges and Translation for Bone Regeneration. Biomaterials 2016, 83, 363-382. [CrossRef]

101. Lopes, D.; Martins-Cruz, C.; Oliveira, M.B.; Mano, J.F. Bone Physiology as Inspiration for Tissue Regenerative Therapies. Biomaterials 2018, 185, 240-275. [CrossRef] 
102. Augusto Oshiro, J.; Rillo Sato, M.; Rocha Scardueli, C.; Jose Pimentel Lopes de Oliveira, G.; Paiva Abucafy, M.; Chorilli, M. Bioactive Molecule-Loaded Drug Delivery Systems to Optimize Bone Tissue Repair. Curr. Protein Pept. Sci. 2017, 18, 850-863. [CrossRef]

103. Wang, T.; Zhai, Y.; Nuzzo, M.; Yang, X.; Yang, Y.; Zhang, X. Layer-by-Layer Nanofiber-Enabled Engineering of Biomimetic Periosteum for Bone Repair and Reconstruction. Biomaterials 2018, 182, 279-288. [CrossRef]

104. Xia, Y.; Sun, J.; Zhao, L.; Zhang, F.; Liang, X.-J.; Guo, Y.; Weir, M.D.; Reynolds, M.A.; Gu, N.; Xu, H.H.K. Magnetic Field and Nano-Scaffolds with Stem Cells to Enhance Bone Regeneration. Biomaterials 2018, 183, 151-170. [CrossRef] [PubMed]

105. Childers, D.L.; Corman, J.; Edwards, M.; Elser, J.J. Sustainability Challenges of Phosphorus and Food: Solutions from Closing the Human Phosphorus Cycle. BioScience 2011, 61, 117-124. [CrossRef]

106. Pravst, I. Risking Public Health by Approving Some Health Claims?-The Case of Phosphorus. Food Policy 2011, 36, 726-728. [CrossRef]

107. Cui, L.; Houston, D.A.; Farquharson, C.; MacRae, V.E. Characterisation of Matrix Vesicles in Skeletal and Soft Tissue Mineralisation. Bone 2016, 87, 147-158. [CrossRef]

108. González Díaz, E.C.; Shih, Y.-R.V.; Nakasaki, M.; Liu, M.; Varghese, S. Mineralized Biomaterials Mediated Repair of Bone Defects Through Endogenous Cells. Tissue Eng. Part A 2018, 24, 1148-1156. [CrossRef]

109. Island, J.O.; Steele, G.A.; van der Zant, H.S.J.; Castellanos-Gomez, A. Environmental Instability of Few-Layer Black Phosphorus. 2D Mater. 2015, 2, 011002. [CrossRef]

110. Rashdan, N.A.; Rutsch, F.; Kempf, H.; Váradi, A.; Lefthériotis, G.; MacRae, V.E. New Perspectives on Rare Connective Tissue Calcifying Diseases. Curr. Opin. Pharmacol. 2016, 28, 14-23. [CrossRef]

111. Nørgaard, R.; Kassem, M.; Rattan, S. Heat Shock-Induced Enhancement of Osteoblastic Differentiation of HTERT-Immortalized Mesenchymal Stem Cells. Ann. N. Y. Acad. Sci. 2006. [CrossRef]

112. Miao, Y.; Shi, X.; Li, Q.; Hao, L.; Liu, L.; Liu, X.; Chen, Y.; Wang, Y. Engineering Natural Matrices with Black Phosphorus Nanosheets to Generate Multi-Functional Therapeutic Nanocomposite Hydrogels. Biomater. Sci. 2019, 7, 4046-4059. [CrossRef]

113. Wang, X.; Shao, J.; Abd El Raouf, M.; Xie, H.; Huang, H.; Wang, H.; Chu, P.K.; Yu, X.-F.; Yang, Y.; AbdEl-Aal, A.M. Near-Infrared Light-Triggered Drug Delivery System Based on Black Phosphorus for in Vivo Bone Regeneration. Biomaterials 2018, 179, 164-174. [CrossRef] [PubMed]

114. Chen, W.; Ouyang, J.; Liu, H.; Chen, M.; Zeng, K.; Sheng, J.; Liu, Z.; Han, Y.; Wang, L.; Li, J.; et al. Black Phosphorus NanosheetBased Drug Delivery System for Synergistic Photodynamic/Photothermal/Chemotherapy of Cancer. Adv. Mater. 2017, 29, 1603864. [CrossRef] [PubMed]

115. Shao, J.; Xie, H.; Huang, H.; Li, Z.; Sun, Z.; Xu, Y.; Xiao, Q.; Yu, X.-F.; Zhao, Y.; Zhang, H.; et al. Biodegradable Black PhosphorusBased Nanospheres for in Vivo Photothermal Cancer Therapy. Nat. Commun. 2016, 7, 12967. [CrossRef] [PubMed]

116. Liu, Y.; Zhu, D.; Zhu, X.; Cai, G.; Wu, J.; Chen, M.; Du, P.; Chen, Y.; Liu, W.; Yang, S. Enhancing the Photodynamic Therapy Efficacy of Black Phosphorus Nanosheets by Covalently Grafting Fullerene C60. Chem. Sci. 2020. [CrossRef]

117. Liu, G.; Tsai, H.I.; Zeng, X.; Qi, J.; Luo, M.; Wang, X.; Mei, L.; Deng, W. Black Phosphorus Nanosheets-Based Stable Drug Delivery System via Drug-Self-Stabilization for Combined Photothermal and Chemo Cancer Therapy. Chem. Eng. J. 2019, 121917. [CrossRef]

118. Li, Y.; Liu, Z.; Hou, Y.; Yang, G.; Fei, X.; Zhao, H.; Guo, Y.; Su, C.; Wang, Z.; Zhong, H.; et al. Multifunctional Nanoplatform Based on Black Phosphorus Quantum Dots for Bioimaging and Photodynamic/Photothermal Synergistic Cancer Therapy. ACS Appl. Mater. Interfaces 2017, 9, 25098-25106. [CrossRef]

119. Xia, F.; Wang, H.; Xiao, D.; Dubey, M.; Ramasubramaniam, A. Two-Dimensional Material Nanophotonics. Nat. Photonics 2014, 8, 899-907. [CrossRef]

120. Ling, X.; Wang, H.; Huang, S.; Xia, F.; Dresselhaus, M.S. The Renaissance of Black Phosphorus. Proc. Natl. Acad. Sci. 2015, 112, 4523-4530. [CrossRef]

121. Shao, J.; Ruan, C.; Xie, H.; Li, Z.; Wang, H.; Chu, P.K.; Yu, X.-F. Black-Phosphorus-Incorporated Hydrogel as a Sprayable and Biodegradable Photothermal Platform for Postsurgical Treatment of Cancer. Adv. Sci. 2018, 5, 1700848. [CrossRef]

122. Li, Z.; Guo, T.; Hu, Y.; Qiu, Y.; Liu, Y.; Wang, H.; Li, Y.; Chen, X.; Song, J.; Yang, H. A Highly Effective $\pi-\pi$ Stacking Strategy To Modify Black Phosphorus with Aromatic Molecules for Cancer Theranostics. ACS Appl. Mater. Interfaces 2019, 11, 9860-9871. [CrossRef]

123. Yang, G.; Liu, Z.; Li, Y.; Hou, Y.; Fei, X.; Su, C.; Wang, S.; Zhuang, Z.; Guo, Z. Facile Synthesis of Black Phosphorus-Au Nanocomposites for Enhanced Photothermal Cancer Therapy and Surface-Enhanced Raman Scattering Analysis. Biomater. Sci. 2017, 5, 2048-2055. [CrossRef] [PubMed]

124. Zhou, W.; Pan, T.; Cui, H.; Zhao, Z.; Chu, P.K.; Yu, X.-F. Black Phosphorus: Bioactive Nanomaterials with Inherent and Selective Chemotherapeutic Effects. Angew. Chem. Int. Ed Engl. 2019, 58, 769-774. [CrossRef] [PubMed]

125. Wan, S.; Zhang, B.; Li, S.; He, B.; Pu, Y. Combination of PEG-Decorated Black Phosphorus Nanosheets and Immunoadjuvant for Photoimmunotherapy of Melanoma. J. Mater. Chem. B 2020, 8, 2805-2813. [CrossRef] [PubMed]

126. Yang, D.; Yang, G.; Yang, P.; Lv, R.; Gai, S.; Li, C.; He, F.; Lin, J. Assembly of Au Plasmonic Photothermal Agent and Iron Oxide Nanoparticles on Ultrathin Black Phosphorus for Targeted Photothermal and Photodynamic Cancer Therapy. Adv. Funct. Mater. 2017. [CrossRef] 
127. Luo, M.; Cheng, W.; Zeng, X.; Mei, L.; Liu, G.; Deng, W. Folic Acid-Functionalized Black Phosphorus Quantum Dots for Targeted Chemo-Photothermal Combination Cancer Therapy. Pharmaceutics 2019, 11, 242. [CrossRef] [PubMed]

128. Yang, X.; Wang, D.; Zhu, J.; Xue, L.; Ou, C.; Wang, W.; Lu, M.; Song, X.; Dong, X. Functional Black Phosphorus Nanosheets for Mitochondria-Targeting Photothermal/Photodynamic Synergistic Cancer Therapy. Chem. Sci. 2019, 10, 3779-3785. [CrossRef]

129. Liu, Q.; Fan, T.; Zheng, Y.; Yang, S.; Yu, Z.; Duo, Y.; Zhang, Y.; Adah, D.; Shi, L.; Sun, Z.; et al. Immunogenic Exosome-Encapsulated Black Phosphorus Nanoparticles as an Effective Anticancer Photo-Nanovaccine. Nanoscale 2020, 12, 19939-19952. [CrossRef]

130. Luo, M.; Zhou, Y.; Gao, N.; Cheng, W.; Wang, X.; Cao, J.; Zeng, X.; Liu, G.; Mei, L. Mesenchymal Stem Cells Transporting Black Phosphorus-Based Biocompatible Nanospheres: Active Trojan Horse for Enhanced Photothermal Cancer Therapy. Chem. Eng. J. 2020, 385, 123942. [CrossRef]

131. Qiu, M.; Wang, D.; Liang, W.; Liu, L.; Zhang, Y.; Chen, X.; Sang, D.K.; Xing, C.; Li, Z.; Dong, B.; et al. Novel Concept of the Smart NIR-Light-Controlled Drug Release of Black Phosphorus Nanostructure for Cancer Therapy. Proc. Natl. Acad. Sci. 2018, 115, 501-506. [CrossRef]

132. Liang, X.; Ye, X.; Wang, C.; Xing, C.; Miao, Q.; Xie, Z.; Chen, X.; Zhang, X.; Zhang, H.; Mei, L. Photothermal Cancer Immunotherapy by Erythrocyte Membrane-Coated Black Phosphorus Formulation. J. Controlled Release 2019, 296, 150-161. [CrossRef]

133. Xing, C.; Chen, S.; Qiu, M.; Liang, X.; Liu, Q.; Zou, Q.; Li, Z.; Xie, Z.; Wang, D.; Dong, B.; et al. Conceptually Novel Black Phosphorus/Cellulose Hydrogels as Promising Photothermal Agents for Effective Cancer Therapy. Adv. Healthc. Mater. 2018, 7, 1701510. [CrossRef] [PubMed]

134. Chen, L.; Chen, C.; Chen, W.; Li, K.; Chen, X.; Tang, X.; Xie, G.; Luo, X.; Wang, X.; Liang, H.; et al. Biodegradable Black Phosphorus Nanosheets Mediate Specific Delivery of HTERT SiRNA for Synergistic Cancer Therapy. ACS Appl. Mater. Interfaces 2018, 10, 21137-21148. [CrossRef] [PubMed]

135. Li, Z.; Xu, H.; Shao, J.; Jiang, C.; Zhang, F.; Lin, J.; Zhang, H.; Li, J.; Huang, P. Polydopamine-Functionalized Black Phosphorus Quantum Dots for Cancer Theranostics. Appl. Mater. Today 2019, 15, 297-304. [CrossRef]

136. Jana, D.; Jia, S.; Bindra, A.K.; Xing, P.; Ding, D.; Zhao, Y. Clearable Black Phosphorus Nanoconjugate for Targeted Cancer Phototheranostics. ACS Appl. Mater. Interfaces 2020, 12, 18342-18351. [CrossRef] [PubMed]

137. Yang, X.; Wang, D.; Shi, Y.; Zou, J.; Zhao, Q.; Zhang, Q.; Huang, W.; Shao, J.; Xie, X.; Dong, X. Black Phosphorus Nanosheets Immobilizing Ce6 for Imaging-Guided Photothermal/Photodynamic Cancer Therapy. ACS Appl. Mater. Interfaces 2018, 10, 12431-12440. [CrossRef] [PubMed]

138. Zhao, H.; Chen, H.; Guo, Z.; Zhang, W.; Yu, H.; Zhuang, Z.; Zhong, H.; Liu, Z. In Situ Photothermal Activation of Necroptosis Potentiates Black Phosphorus-Mediated Cancer Photo-Immunotherapy. Chem. Eng. J. 2020, 394, 124314. [CrossRef]

139. Su, Y.; Wang, T.; Su, Y.; Li, M.; Zhou, J.; Zhang, W.; Wang, W. A Neutrophil Membrane-Functionalized Black Phosphorus Riding Inflammatory Signal for Positive Feedback and Multimode Cancer Therapy. Mater. Horiz. 2020, 7, 574-585. [CrossRef]

140. Schreml, S.; Szeimies, R.-M.; Prantl, L.; Landthaler, M.; Babilas, P. Wound Healing in the 21st Century. J. Am. Acad. Dermatol. 2010, 63, 866-881. [CrossRef]

141. Martin, P.; Nunan, R. Cellular and Molecular Mechanisms of Repair in Acute and Chronic Wound Healing. Br. J. Dermatol. 2015, 173, 370-378. [CrossRef]

142. Ahmadi, M.; Adibhesami, M. The Effect of Silver Nanoparticles on Wounds Contaminated with Pseudomonas Aeruginosa in Mice: An Experimental Study. Iran. J. Pharm. Res. IJPR 2017, 16, 661.

143. Biondi-Zoccai, G.G.; Lotrionte, M.; Agostoni, P.; Abbate, A.; Fusaro, M.; Burzotta, F.; Testa, L.; Sheiban, I.; Sangiorgi, G. A Systematic Review and Meta-Analysis on the Hazards of Discontinuing or Not Adhering to Aspirin among 50279 Patients at Risk for Coronary Artery Disease. Eur. Heart J. 2006, 27, 2667-2674. [CrossRef] [PubMed]

144. Parani, M.; Lokhande, G.; Singh, A.; Gaharwar, A.K. Engineered Nanomaterials for Infection Control and Healing Acute and Chronic Wounds. ACS Appl. Mater. Interfaces 2016, 8, 10049-10069. [CrossRef] [PubMed]

145. Huang, X.-W.; Wei, J.-J.; Zhang, M.-Y.; Zhang, X.-L.; Yin, X.-F.; Lu, C.-H.; Song, J.-B.; Bai, S.-M.; Yang, H.-H. Water-Based Black Phosphorus Hybrid Nanosheets as a Moldable Platform for Wound Healing Applications. ACS Appl. Mater. Interfaces 2018, 10, 35495-35502. [CrossRef] [PubMed]

146. Dugger, B.N.; Dickson, D.W. Pathology of Neurodegenerative Diseases. Cold Spring Harb. Perspect. Biol. 2017, 9. [CrossRef]

147. Baquero, M.; Martín, N. Depressive Symptoms in Neurodegenerative Diseases. World J. Clin. Cases WJCC $2015,3,682-693$. [CrossRef]

148. Hurley, L.L.; Tizabi, Y. Neuroinflammation, Neurodegeneration and Depression. Neurotox. Res. 2013, 23, 131-144. [CrossRef]

149. Wyss-Coray, T. Ageing, Neurodegeneration and Brain Rejuvenation. Nature 2016, 539, 180-186. [CrossRef]

150. Furtado, D.; Björnmalm, M.; Ayton, S.; Bush, A.I.; Kempe, K.; Caruso, F. Overcoming the Blood-Brain Barrier: The Role of Nanomaterials in Treating Neurological Diseases. Adv. Mater. 2018, 30, 1801362. [CrossRef]

151. Dong, X. Current Strategies for Brain Drug Delivery. Theranostics 2018, 8, 1481-1493. [CrossRef]

152. Xiong, S.; Li, Z.; Liu, Y.; Wang, Q.; Luo, J.; Chen, X.; Xie, Z.; Zhang, Y.; Zhang, H.; Chen, T. Brain-Targeted Delivery Shuttled by Black Phosphorus Nanostructure to Treat Parkinson's Disease. Biomaterials 2020, 260, 120339. [CrossRef]

153. Jin, L.; Hu, P.; Wang, Y.; Wu, L.; Qin, K.; Cheng, H.; Wang, S.; Pan, B.; Xin, H.; Zhang, W.; et al. Fast-Acting Black-PhosphorusAssisted Depression Therapy with Low Toxicity. Adv. Mater. 2020, 32, 1906050. [CrossRef] [PubMed] 
154. Pedersen, J.T.; Chen, S.W.; Borg, C.B.; Ness, S.; Bahl, J.M.; Heegaard, N.H.H.; Dobson, C.M.; Hemmingsen, L.; Cremades, N.; Teilum, K. Amyloid- $\beta$ and $\alpha$-Synuclein Decrease the Level of Metal-Catalyzed Reactive Oxygen Species by Radical Scavenging and Redox Silencing. J. Am. Chem. Soc. 2016, 138, 3966-3969. [CrossRef] [PubMed]

155. Zhang, Y.; Zhai, D.; Xu, M.; Yao, Q.; Zhu, H.; Chang, J.; Wu, C. 3D-Printed Bioceramic Scaffolds with Antibacterial and Osteogenic Activity. Biofabrication 2017, 9, 025037. [CrossRef] [PubMed]

156. Shi, W.; Sun, M.; Hu, X.; Ren, B.; Cheng, J.; Li, C.; Duan, X.; Fu, X.; Zhang, J.; Chen, H. Structurally and Functionally Optimized Silk-fibroin-Gelatin Scaffold Using 3D Printing to Repair Cartilage Injury in Vitro and in Vivo. Adv. Mater. 2017, $29,1701089$. [CrossRef] [PubMed]

157. Li, Y.; Liu, C. Nanomaterial-Based Bone Regeneration. Nanoscale 2017, 9, 4862-4874. [CrossRef] [PubMed]

158. Yang, B.; Yin, J.; Chen, Y.; Pan, S.; Yao, H.; Gao, Y.; Shi, J. 2D-Black-Phosphorus-Reinforced 3D-Printed Scaffolds:A Stepwise Countermeasure for Osteosarcoma. Adv. Mater. 2018, 30, 1705611. [CrossRef] [PubMed]

159. Liu, X.; Miller, A.L.; Park, S.; George, M.N.; Waletzki, B.E.; Xu, H.; Terzic, A.; Lu, L. Two-Dimensional Black Phosphorus and Graphene Oxide Nanosheets Synergistically Enhance Cell Proliferation and Osteogenesis on 3D Printed Scaffolds. ACS Appl. Mater. Interfaces 2019, 11, 23558-23572. [CrossRef]

160. Wang, C.; Ye, X.; Zhao, Y.; Bai, L.; He, Z.; Tong, Q.; Xie, X.; Zhu, H.; Cai, D.; Zhou, Y. Cryogenic 3D Printing of Porous Scaffolds for in Situ Delivery of 2D Black Phosphorus Nanosheets, Doxorubicin Hydrochloride and Osteogenic Peptide for Treating Tumor Resection-Induced Bone Defects. Biofabrication 2020, 12, 035004. [CrossRef]

161. Kunjachan, S.; Ehling, J.; Storm, G.; Kiessling, F.; Lammers, T. Noninvasive Imaging of Nanomedicines and Nanotheranostics: Principles, Progress, and Prospects. Chem. Rev. 2015, 115, 10907-10937. [CrossRef]

162. Ding, K.; Zeng, J.; Jing, L.; Qiao, R.; Liu, C.; Jiao, M.; Li, Z.; Gao, M. Aqueous Synthesis of PEGylated Copper Sulfide Nanoparticles for Photoacoustic Imaging of Tumors. Nanoscale 2015, 7, 11075-11081. [CrossRef]

163. Luke, G.P.; Yeager, D.; Emelianov, S.Y. Biomedical Applications of Photoacoustic Imaging with Exogenous Contrast Agents. Ann. Biomed. Eng. 2012, 40, 422-437. [CrossRef] [PubMed]

164. Kircher, M.F.; de la Zerda, A.; Jokerst, J.V.; Zavaleta, C.L.; Kempen, P.J.; Mittra, E.; Pitter, K.; Huang, R.; Campos, C.; Habte, F.; et al. A Brain Tumor Molecular Imaging Strategy Using A New Triple-Modality MRI-Photoacoustic-Raman Nanoparticle. Nat. Med. 2012, 18, 829-834. [CrossRef] [PubMed]

165. Kou, L.; Chen, C.; Smith, S.C. Phosphorene: Fabrication, Properties, and Applications. J. Phys. Chem. Lett. 2015, 6, $2794-2805$. [CrossRef] [PubMed]

166. Sun, C.; Wen, L.; Zeng, J.; Wang, Y.; Sun, Q.; Deng, L.; Zhao, C.; Li, Z. One-Pot Solventless Preparation of PEGylated Black Phosphorus Nanoparticles for Photoacoustic Imaging and Photothermal Therapy of Cancer. Biomaterials 2016, 91, 81-89. [CrossRef]

167. Sun, Z.; Zhao, Y.; Li, Z.; Cui, H.; Zhou, Y.; Li, W.; Tao, W.; Zhang, H.; Wang, H.; Chu, P.K.; et al. TiL4 -Coordinated Black Phosphorus Quantum Dots as an Efficient Contrast Agent for In Vivo Photoacoustic Imaging of Cancer. Small Weinh. Bergstr. Ger. 2017, 13. [CrossRef]

168. Engel, M.; Steiner, M.; Avouris, P. Black Phosphorus Photodetector for Multispectral, High-Resolution Imaging. Nano Lett. 2014, 14, 6414-6417. [CrossRef]

169. Choi, J.R.; Yong, K.W.; Choi, J.Y.; Nilghaz, A.; Lin, Y.; Xu, J.; Lu, X. Black Phosphorus and Its Biomedical Applications. Theranostics 2018, 8, 1005-1026. [CrossRef]

170. Zhao, Y.; Tong, L.; Li, Z.; Yang, N.; Fu, H.; Wu, L.; Cui, H.; Zhou, W.; Wang, J.; Wang, H.; et al. Stable and Multifunctional Dye-Modified Black Phosphorus Nanosheets for Near-Infrared Imaging-Guided Photothermal Therapy. Chem. Mater. 2017, 29, 7131-7139. [CrossRef]

171. Zhang, X.; Zhang, Z.; Zhang, S.; Li, D.; Ma, W.; Ma, C.; Wu, F.; Zhao, Q.; Yan, Q.; Xing, B. Size Effect on the Cytotoxicity of Layered Black Phosphorus and Underlying Mechanisms. Small 2017, 13, 1701210. [CrossRef]

172. Lim, C.T. Biocompatibility and Nanotoxicity of Layered Two-Dimensional Nanomaterials. ChemNanoMat 2017, 3, 5-16. [CrossRef]

173. Song, S.-J.; Shin, Y.C.; Lee, H.U.; Kim, B.; Han, D.-W.; Lim, D. Dose- and Time-Dependent Cytotoxicity of Layered Black Phosphorus in Fibroblastic Cells. Nanomaterials 2018, 8, 408. [CrossRef] [PubMed]

174. Lee, H.U.; Park, S.Y.; Lee, S.C.; Choi, S.; Seo, S.; Kim, H.; Won, J.; Choi, K.; Kang, K.S.; Park, H.G.; et al. Black Phosphorus (BP) Nanodots for Potential Biomedical Applications. Small 2016, 12, 214-219. [CrossRef] [PubMed]

175. Latiff, N.M.; Teo, W.Z.; Sofer, Z.; Fisher, A.C.; Pumera, M. The Cytotoxicity of Layered Black Phosphorus. Chem. - Eur. J. 2015, 21, 13991-13995. [CrossRef] [PubMed]

176. Sun, Y.; Fan, S.; Fan, S.; Li, C.; Shang, Z.; Gu, M.; Liang, S.; Tian, X. In Vitro and In Vivo Toxicity of Black Phosphorus Nanosheets. J. Nanosci. Nanotechnol. 2020, 20, 659-667. [CrossRef] [PubMed]

177. Gobaa, S.; Hoehnel, S.; Lutolf, M.P. Substrate Elasticity Modulates the Responsiveness of Mesenchymal Stem Cells to Commitment Cues. Integr. Biol. 2015, 7, 1135-1142. [CrossRef]

178. Tseng, Q.; Wang, I.; Duchemin-Pelletier, E.; Azioune, A.; Carpi, N.; Gao, J.; Filhol, O.; Piel, M.; Théry, M.; Balland, M. A New Micropatterning Method of Soft Substrates Reveals That Different Tumorigenic Signals Can Promote or Reduce Cell Contraction Levels. Lab. Chip 2011, 11, 2231. [CrossRef] 
179. Shin, S.R.; Zihlmann, C.; Akbari, M.; Assawes, P.; Cheung, L.; Zhang, K.; Manoharan, V.; Zhang, Y.S.; Yüksekkaya, M.; Wan, K.; et al. Reduced Graphene Oxide-GelMA Hybrid Hydrogels as Scaffolds for Cardiac Tissue Engineering. Small 2016, 12, 3677-3689. [CrossRef]

180. Shin, S.R.; Jung, S.M.; Zalabany, M.; Kim, K.; Zorlutuna, P.; Kim, S.b.; Nikkhah, M.; Khabiry, M.; Azize, M.; Kong, J.; et al. CarbonNanotube-Embedded Hydrogel Sheets for Engineering Cardiac Constructs and Bioactuators. ACS Nano 2013, 7, 2369-2380. [CrossRef]

181. Sresht, V.; Pádua, A.A.H.; Blankschtein, D. Liquid-Phase Exfoliation of Phosphorene: Design Rules from Molecular Dynamics Simulations. ACS Nano 2015, 9, 8255-8268. [CrossRef]

182. Grimme, S.; Antony, J.; Ehrlich, S.; Krieg, H. A Consistent and Accurate Ab Initio Parametrization of Density Functional Dispersion Correction (DFT-D) for the 94 Elements H-Pu. J. Chem. Phys. 2010, 132. [CrossRef]

183. Marom, N.; Tkatchenko, A.; Rossi, M.; Gobre, V.V.; Hod, O.; Scheffler, M.; Kronik, L. Dispersion Interactions with DensityFunctional Theory: Benchmarking Semiempirical and Interatomic Pairwise Corrected Density Functionals. J. Chem. Theory Comput. 2011, 7, 3944-3951. [CrossRef] [PubMed]

184. Shih, C.J.; Lin, S.; Strano, M.S.; Blankschtein, D. Understanding the Stabilization of Liquid-Phase-Exfoliated Graphene in Polar Solvents: Molecular Dynamics Simulations and Kinetic Theory of Colloid Aggregation. J. Am. Chem. Soc. 2010, 132, 14638-14648. [CrossRef] [PubMed]

185. Kamath, G.; Baker, G.A. Are Ionic Liquids Suitable Media for Boron Nitride Exfoliation and Dispersion? Insight via Molecular Dynamics. RSC Adv. 2013, 3, 8197-8202. [CrossRef]

186. Kamath, G.; Baker, G.A. In Silico Free Energy Predictions for Ionic Liquid-Assisted Exfoliation of a Graphene Bilayer into Individual Graphene Nanosheets. Phys. Chem. Chem. Phys. 2012, 14, 7929-7933. [CrossRef]

187. Ludwig, T.; Guo, L.; Mccrary, P.; Zhang, Z.; Gordon, H.; Quan, H.; Stanton, M.; Frazier, R.M.; Rogers, R.D.; Wang, H.T.; et al. Mechanism of Bismuth Telluride Exfoliation in an Ionic Liquid Solvent. Langmuir 2015, 31, 3644-3652. [CrossRef]

188. Luo, M.; Fan, T.; Zhou, Y.; Zhang, H.; Mei, L. 2D Black Phosphorus-Based Biomedical Applications. Adv. Funct. Mater. 2019, 29, 1808306. [CrossRef]

189. Konvalina, G.; Haick, H. Sensors for Breath Testing: From Nanomaterials to Comprehensive Disease Detection. Acc. Chem. Res. 2014, 47, 66-76. [CrossRef] 